\title{
Synthesis, Characterization and Evaluation of Amphoteric Galactomannan Derivative for the Mitigation of Malachite Green and Congo Red Dye From Aqueous Solution
}

\section{Deepak Sharma}

Forest Research Institute Dehradun

Vineet Madan

Forest Research Institute Dehradun

Pradeep Sharma ( $\sim$ drsharma27@gmail.com )

Forest Research Institute Dehradun https://orcid.org/0000-0002-5960-5931

\section{Research Article}

Keywords: Biopolymer, Dyes, Galactomannan, Adsorption, Dyes, Polysaccharide

Posted Date: April 5th, 2021

DOI: https://doi.org/10.21203/rs.3.rs-352705/v1

License: (c) (1) This work is licensed under a Creative Commons Attribution 4.0 International License. Read Full License

Version of Record: A version of this preprint was published at Cellulose on January 14th, 2022. See the published version at https://doi.org/10.1007/s10570-021-04332-5. 


\title{
Synthesis, characterization and evaluation of amphoteric galactomannan derivative for the mitigation of malachite green and congo red dye from aqueous solution
}

\author{
Deepak Sharma $^{\mathrm{a}}$, Vineet Kumar ${ }^{\mathrm{a}}$, and Pradeep Sharma ${ }^{\mathrm{a}^{*}}$ \\ ${ }^{a}$ Chemistry and Bioprospecting Division \\ Forest Research Institute Dehradun-248006 \\ Indian Council of Forestry Research and Education
}

\begin{abstract}
Biopolymeric materials have been utilized for water treatments since ancient times. Consequently, there is a cumulative and persistent interest in the study of novel sustainable, inexpensive and natural biobased alternatives. Amphoteric derivatives of galactomannans are still unexplored and rarerly used materials to treat industrial wastes. The study was explored to synthesize and characterize amphoteric derivative of Cassia tora gum, a 1,5 galactomannan for its application as a potential adsorbent for mitigation of cationic (Malachite green) and anionic (Congo red) dyes by applying 'Taguchi design' (L9). The derivative was also studied for the conditioning of water using kaolin suspension. The results indicated that amphoteric derivative (anionic DS 0.52 and cationic DS 0.197) is effective in maximum adsorption of Malachite green (73\%) and Congo red (17\%) dyes and as a flocculant at a minimum dose of $10 \mathrm{ppm}$. The amphoteric derivative was characterized by Xray-diffraction, TG analysis and spectroscopic techniques.
\end{abstract}

Keywords: Biopolymer, Dyes, Galactomannan, Adsorption, Dyes, Polysaccharide

Corresponding author: Chemistry and Bioprospecting Division, Forest Research Institute Dehradun-248006, Uttarakhand, India E-mail addresses: drsharma27@gmail.com; sharmap@icfre.org (Pradeep Sharma). 


\section{Introduction}

The developing concerns of water scarcity and environmental sustainability consciousness have renewed the global awareness towards the functional reuse and treatment of extremely contaminated wastewater (Grant et al., 2012). Water pollution caused by synthetic dyes and its threat on environment has significantly attracted the worldwide attention (Xie et al., 2014). Water soluble dyes possessing cationic, anionic, and non-ionic groups are widely being used in diverse industrial segments leading to water pollution due to their persistent growth and progress in numerous industries such as textiles, leather, paper production, pharmaceutical and food technology etc (Gupta, 2009; Chen et al., 2009; Gharbani et al., 2009; Cripps et al., 2009; Karadag et al., 2006; Reed et al., 1998). According to a report $>50000$ ton of dye is released in dyeing process causing serious environmental threat (Blackburn, 2009). The presence of dyeing effluent in a watercourse has a severe environmental impact as they are highly visible, non-biodegradable, toxic, and further, potentially able to be transformed into carcinogenic, teratogenic, and even mutagenic agents, creating a serious threat to human health and marine organisms (Sansuk et al., 2016). In the textile industry, generation of wastewater is chemically contaminated with dyestuffs, inorganic salts and other chemicals (Han et al., 2017). The release of such extremely contaminated wastewater into aquatic environments not only causes deleterious consequences to the aquatic ecosystems and public health yet additionally decreases the measure of accessible water. The unceasing exposure of colouring matter and their intermediates are responsible carcinogens and to a lesser extent sensitizers and allergens (Horng \& Huang, 1993). Malachite green (MG), a cationic dye and Congo red (CR), an anionic dye are water soluble dyes and consistently used in the textile and paper industries (Kolya \& Tripathi, 2013; Rao, 1995; Becki et al., 2008; Ahmad \& Kumar, 2010). Intriguingly, these dyes are harmful due to their toxic and carcinogenic thrust 
and as a liver tumour promoter to the mammals (Srivastava et al., 2004; Culp \& Beland; 1996; Rao, 1995).

The effective treatment and retrieval of the severely polluted water before returning to the biological system have become a significant issue. Therefore, efficient methods of separation and removal of water contaminants are required to cope with hazardous situation (Sansuk, 2016; Han, 2016). In principle, diverse methods are utilized for decolouration viz.: , coagulation, biodegradation, chemical degradation, and photodegradation (Bouaziz, 2017). Further, reducing the turbidity of industrial and municipal waste water by coagulationflocculation treatment is a well-known process. The polymers with anionic and cationic amalgamation have been used in the coagulation-flocculation process to reduce coagulant dosages, the volume of sludge and the ionic load of the waste-water and further, to reduce overall costs (Yan et al., 2009; Larsson \& Wall, 1998; Ovenden \& Xiao, 2002; Sirviö et al., 2011). Generally synthetic polymers viz., poly-acrylamides, polyacrylic acids, and polystyrene sulphonic acid and their derivatives are used in coagulation-flocculation treatments which are not readily biodegradable and also behave as neurotoxic and carcinogenic (Suopajärvi, 2013; Suopajärvi et al., 2014). Alternatively, green biopolymers viz. starch, guar gum, chitin, pectin and algin, and their derivatives have been studied as biopolymeric materials, for the treatment of wastewater as dye adsorbent and flocculants due to their biodegradable nature and safe to human beings (Wang et al., 2013).

The galactomannan obtained from the seeds of $C$. tora Linn. a ruderal species (Family: Leguminosae; subfamily: Caesalpiniaceae(Pawar\&D'mello, 2011; Sharma et al., 2020a; Sharma et al., 2020b) is of developing interest because of its non-toxicity, safety, biodegradability, biocompatibility, renewability and sustainability (Thombare et al., 2016). It possesses main chain comprised of $(1 \rightarrow 4)-\beta$-D-mannopyranose $($ Man) units which are attached to $(1 \rightarrow 6)-\alpha$-D-galactopyranose (Gal) units with M: G, 5:1 (Hallagan et al., 1997). C. 
tora gum has owned its limitations due to its unique structure and performance thereof in its native form. The functional properties of the galactomannans significantly affect the degree of their application. Incorporation of new functional moieties onto the galactomannans intensifies ingenious property, polarity and hydrophilicity, which enhance the interaction of the gum with various compounds. Quaternization and carboxymethylation are well-known derivatization processes for imparting the new functional properties to the galactomannans. Quaternization and carboxymethylation of polysaccharides viz. cellulose, starch, chitosan and galactomannans, are regarded as safe strategy to synthesize functional polysaccharides to impart new distinctive characteristics like high water solubility, antibacterial activity, and conditioning property in hair styling products, anionic dye capacity and flocculant in waste water treatments (Novac et al., 2014), and hydrophilicity, solution clarity, stability in aqueous systems and to enhance biological activities by changing their molecular structure, dye adsorbent and flocculant in waste water treatments (Thombare et al., 2016; Dodi et al., 2011; Heinze \& Koschella, 2005; Huang et al., 2016; Xu et al., 2019; Narayanan et a., 2014; Rahul et al., 2014).

The present study aimed to assess the perceived design and synthesis of a water-soluble hybrid novel amphoteric derivative of $C$. tora gum (CMQCTG), having the amalgamation of both anionic and cationic nature, for removal of cationic (MG) and anionic (CR) dyes and as a flocculant over a dispersion of kaolin in water. A systematic statistical design i.e., Taguchi 'L9' was used to conduct the experiment for optimizing the parameters viz. adsorbent dosage, temperature, and time for the dye removal process. The synthesized amphoteric product was characterized by ${ }^{1} \mathrm{H},{ }^{13} \mathrm{C}$, DEPT-135, HSQC NMR, FTIR, FESEM, X-ray diffraction, and TG analysis. 


\section{EXPERIMENTAL SECTION}

\subsection{Materials}

C. tora gum was procured from M/s Goodrich Cereals Haryana, India. The quaternizing reagent 3-chloro-2-hydroxypropyltrimethylammonium chloride (CHPTAC, 60 wt. \% aqueous), and deuterium oxide were procured from Sigma-Aldrich, St. Louis, Missouri, USA. Monochloroacetic acid (MCA), sodium hydroxide, isopropanol, methanol, and acetic acid were purchased from Merck India Ltd., Mumbai, India. Malachite green, Congo red dye and Kaolin extra pure was purchased from Loba Chemie Pvt. Ltd.

\subsection{Methods}

\subsubsection{Synthesis of carboxymethyl and quaternized Cassia tora gum (CMQCTG)}

C. tora gum (CTG, 100 mesh, $0.03075 \mathrm{~mol})$ was dispersed in aqueous alkaline $(0.15 \mathrm{~mol})$ isopropanol solution (isopropanol: water, 80:20, v/v). The reaction flask was kept on a magnetic stirrer for continuous stirring at a temperature $50^{\circ} \mathrm{C}$. After 10 minutes, MCA $(0.0396, \mathrm{~mol})$ was added in parts and continuous stirred for $60 \mathrm{~min}$. To this reaction mixture (pH 12.9) CHPTAC (0.00478-0.0319 mol) was added and the reaction mixture was further stirred for 240 min (Sharma et al., 2020a). Intriguingly, the $\mathrm{pH}$ depends upon the addition of varying amount of CHPTAC, therefore, the $\mathrm{pH}$ of the reaction mixture was measured during and after the completion of each reaction. The reaction product was filtered under vacuum after designated reaction time, dispersed in distilled water and an aqueous acetic acid (5\%, v/v) was added drop wise to neutralize the solution. The neutralized reaction mixture was subjected to precipitation with methanol. The precipitated product was separated by centrifugation (15000 rpm for $12 \mathrm{~min}$ ) followed by washing with $80 \%$ aqueous methanol $(3 \times 20 \mathrm{~mL})$ and finally with pure methanol. The purified dual derivative (CMQCTG) was dried in the oven at $60^{\circ} \mathrm{C}$ for $6 \mathrm{hrs}$. 


\subsubsection{Preparation of Malachite green (MG) and Congo red (CR) solution for optimizing adsorption capacity of CMQCTG}

Stock solution of MG and CR (100 ppm) was prepared by dissolving $0.1 \mathrm{~g}$ of dye into $1.0 \mathrm{~L}$ distilled water (Koyla \& Tripathy, 2013). Calibration curves for MG and CR (5 to 25 ppm) were prepared to determine the concentration of residual dyes in the experiments. The concentration of dye in the experimental solutions was determined by UV-VIS spectrophotometer (Chemito-2700) at $\lambda \max 617$ and $495 \mathrm{~nm}$ respectively. Analysis was carried out using the CMQCTG as a cationic and anionic adsorbent. Taguchi L9 array, a statistical design of experiment was used for optimizing the parameters for MG and CR. The operating variables like degree of substitution (DS), amount of adsorbent, temperature, and contact time were the four factors with three sub levels for optimization process. For dye experiments, CMQCTG, (cationic DS, 0.023, 0.123, \&0.197; anionic DS, 0.52) with different dose amount $(10,25, \& 50 \mathrm{mg})$ was added to a $30 \mathrm{~mL}$ of dye solution $(25 \mathrm{ppm})$ in a100 $\mathrm{mL}$ beaker. The dye solution was stirred for a stipulated time $(60,120$, \& $190 \mathrm{~min})$ and temperature $\left(25,35, \& 45^{\circ} \mathrm{C}\right)$. Finally, the solution was allowed to settle for five minutes. The supernatant liquid at half the height of the beaker was taken for the analysis by UV-VIS spectrophotometer. The percentage of dye was calculated using the formula given in eqn no 1.

$$
\text { Adsorption } \%=\frac{(C o-C e)}{C o} * 100
$$

Where $C o$ is the initial dye concentration, $C e$ is the final concentration obtained after adding the adsorbent.

\subsubsection{Flocculation Test}

Flocculation performance of the CMQCTG was carried out using Coagulation-Flocculation jar tests (Bratby, 1980). A suspension of kaolin in water (1\%, w/v) was dispersed in five 250 
mL beakers. The CMQCTG (10-50 ppm) was added to the beakers. Immediately after the addition of the CMQCTG, all the suspensions were stirred using magnetic bars at a constant speed of $100 \mathrm{r} / \mathrm{min}$ for 2 minutes followed by a slow agitation at $50 \mathrm{rpm}$ for 5 minutes (flocculating time). The flocs were then allowed to settle down for 2 minutes (sedimentation time). At the end of the settling period, the absorbance of supernatant liquid at half the height of the clarified layer was measured using a UV-VIS spectrophotometer (Chemito-2700) at $670 \mathrm{~nm}$.

\section{CHARACTERIZATION OF CMQCTG}

\subsection{Elemental analyses}

The nitrogen content of CMQCTG samples was determined by the Kjeldahl method.

\subsection{Determination of degree of substitution (DS)}

The DS for quaternisation of all the CMQCTG samples was determined on the basis of an increase in nitrogen content using the following formula (Heinze et al., 2004):

$$
D S=\frac{162.2 \times \% \text { Nitrogen }}{1401-151.6 \times \% \text { Nitrogen }}
$$

The DS for carboxymethylation was determined according to a reported method with minor modifications (ASTM D1439-15, 2015). CMQCTG (500 mg) was converted into acid form by treating with $0.1 \mathrm{M}$ aqueous methanolic $\mathrm{HCl}$ (methanol:water::90:10, 50mL) in a $250 \mathrm{~mL}$ beaker with continuous stirring for $2 \mathrm{hrs}$. The solution was filtered and washed under suction using a G-4 sintered glass funnel with aqueous methanol (methanol: water::90:10, 8x20 mL) and finally with pure methanol. The resulting sample was dried in the oven at $100^{\circ} \mathrm{C}$ for $1 \mathrm{hr}$ and kept in a vacuum desiccator. The desiccated sample $(250 \mathrm{mg})$ was dispersed in double distilled water $(100 \mathrm{~mL})$ and treated with alkaline solution $(10 \mathrm{~mL}, 0.1 \mathrm{M} \mathrm{NaOH})$ in a $250 \mathrm{~mL}$ conical flask. The flask was kept for stirring at $70^{\circ} \mathrm{C}$ until a clear solution $(20-30$ min) 
obtained. The solution at this stage was titrated with $0.1 \mathrm{M} \mathrm{HCl}$ using phenolphthalein as an indicator. The degree of etherification $(\mathrm{G})$ was calculated as follows:

$$
A=\frac{(B C-D E)}{F}
$$

Where;

$\mathrm{A}=$ milliequivalents of acid consumed per gram of sample

$\mathrm{B}=\mathrm{NaOH}$ solution added, $\mathrm{mL}$

$\mathrm{C}=$ molarity of $\mathrm{NaOH}$ solution added

$\mathrm{D}=\mathrm{HCl}$ required for titration of excess $\mathrm{NaOH}, \mathrm{mL}$

$\mathrm{E}=$ molarity of $\mathrm{HCl}$

$\mathrm{F}=$ weight of CMCTG, $\mathrm{g}$

(1)

$$
G=\frac{0.162 A}{(1-0.0584 A)}
$$

Where;

162 = gram molecular mass of anhydroglucose unit of CTG, and

$58=$ net increase in molecular mass of anhydroglucose unit for each carboxymethyl group substituted.

\subsection{Infrared spectroscopy}

FT-IR spectra were recorded on a Fourier transform infrared (FT-IR) spectrophotometer (Perkin Elmer-Spectrum II). Samples (2-3 mg) were blended with spectroscopic KBr powder (100 mg) and pellets prepared for recording the spectrum. The spectra were acquired by the accumulation of 16 scans, with a resolution of $4 \mathrm{~cm}^{-1}$, at $400-4000 \mathrm{~cm}^{-1}$.

\section{4. ${ }^{1} \mathrm{H},{ }^{13} \mathrm{C}$, DEPT-135 and 2D NMR (HSQC) spectroscopy}

The NMR spectra of CTG and CMQCTG were acquired using a 500MHz Bruker spectrometer at $25^{\circ} \mathrm{C}$. The samples were hydrolysed prior to recording the spectra. CTG $(0.5$ 
g) was treated with aqueous sulfuric acid solution $(20 \%, 50 \mathrm{~mL})$ and stirred for $30 \mathrm{~min}$ at $50^{\circ} \mathrm{C}$. After cooling in a water bath, the reaction mixture was neutralized by saturated sodium bicarbonate solution, and dialyzed against deionized water for $48 \mathrm{hrs}$. The dialysate was

202 filtered and freeze-dried. The freeze-dried sample $(60 \mathrm{mg})$ was dissolved in $1 \mathrm{~mL} \mathrm{D}_{2} \mathrm{O}$ for NMR spectral analysis (Sharma et al., 2020a). Spectral recordings were performed at 303.3K using parameters- ${ }^{1} \mathrm{H}-\mathrm{NMR}$ spectrum: $500.17 \mathrm{MHz}, 32$ scans, $2.2282 \mathrm{~s}$ data acquisition time, $1 \mathrm{~s}$ relaxation delay time; ${ }^{13} \mathrm{C}-\mathrm{NMR}: 125.77 \mathrm{MHz}, 1024$ scans, $0.8847 \mathrm{~s}$ data acquisition time, 2 s relaxation delay time; DEPT-135: 512 scans, $0.8847 \mathrm{~s}$ data acquisition time, $2 \mathrm{~s}$ relaxation delay time; HSQC: 2 scans, $0.1946 \mathrm{~s}$ data acquisition time and 1.500s relaxation delay time.

\subsection{Thermogravimetric analysis}

Thermogravimetric analysis was carried out using $\sim 3 \mathrm{mg}$ of sample in a DTG-60 unit (Shimadzu, Japan) under nitrogen atmosphere with a flow rate of $40 \mathrm{~mL} / \mathrm{min}$. The scan was carried out at a heating rate of $10^{\circ} \mathrm{C} / \mathrm{min}$ from $0^{\circ} \mathrm{C}$ to $800^{\circ} \mathrm{C}$.

\subsection{X-ray diffraction (XRD) analysis}

XRD patterns of powdered samples were acquired using a Bruker D8 Advance (Germany) diffractometer $(30 \mathrm{kV}, 30 \mathrm{~mA})$ equipped with $\mathrm{Cu} \mathrm{K \alpha}$ radiation at a wavelength of $(\lambda=1.5418 \AA)$. The relative intensity was recorded in the scattering range $(2 \theta)$ of $0-90^{\circ}$ at the scanning rate of $2 \%$ min.

\subsection{Field emission scanning electron microscopy (FESEM)}

The field emission scanning electron microscopy was used to study the morphology of CTG and CMQCTG using instrument MIRA3 TESCAN, USA. The sample was mounted on a circular aluminium stub with double sticky tape, coated with gold and the images of samples were captured with an accelerating potential difference of $10 \mathrm{kV}$ at a working distance of 5 $\mathrm{mm}$. 


\section{RESULTS AND DISCUSSIONS}

224 The synthesis of amphoteric derivative proceeds consecutively via Williamson's ether synthesis (Scheme 1) (Su et al., 2019). The substitution of sodium carboxymethyl and quaternary ammonium moiety onto CTG was achieved by etherification, where the alkoxide

227 ion reacts with the MCA and subsequently with the EPTAC (2,3-

228 epoxypropyltrimethylammonium chloride), produced in situ from CHPTAC leading to 229 formation of the amphoteric product (CMQCTG) comprising of carboxymethyl and 230 quaternary ammonium groups. The maximal degree of substitution is achieved when all 231 hydroxyl groups are etherified, however, during the reaction sodium glycolate and 2,3232 dihydroxypropyltrimethylammonium chloride are also formed as by-products simultaneously 233 affects the DS (Sharma et al., 2020a; Su et al., 2019).

234
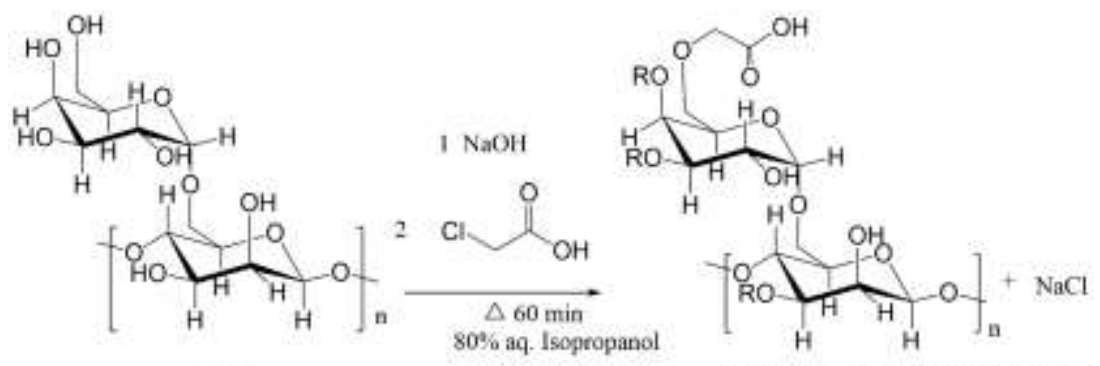

CTG
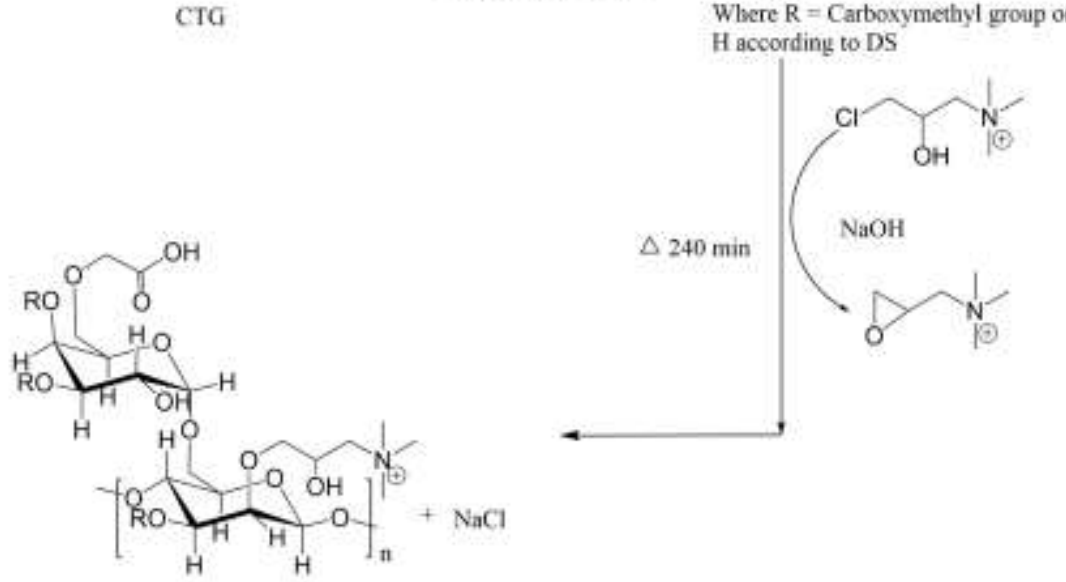

CMQCTG

Whare R - Carboxymethyl, quaternized group

or $\mathrm{H}$ according to DS

SCHEME1. Synthesis of amphoteric derivative 
Table 1. Reaction Parameters and their Influence on Degree of Substitution

\begin{tabular}{|c|c|c|c|c|c|c|c|c|c|}
\hline $\begin{array}{c}\text { Gum } \\
(\mathrm{mol})\end{array}$ & $\begin{array}{c}\text { Tim } \\
\mathrm{e} \\
(\mathrm{hr})\end{array}$ & $\begin{array}{c}\text { Alkali } \\
(\mathrm{mol})\end{array}$ & $\begin{array}{c}\text { MCA } \\
(\mathrm{mol})\end{array}$ & $\begin{array}{c}\text { Temper } \\
\text { ature } \\
\left({ }^{\circ} \mathrm{C}\right)\end{array}$ & $\begin{array}{c}\text { Gum: } \\
\text { Solvent }\end{array}$ & DS* & $\begin{array}{c}\text { CHPTA } \\
\mathrm{C}(\mathrm{mol})\end{array}$ & $\mathrm{pH}$ & DS** \\
\hline 0.03075 & 1 & 0.15 & 0.0396 & 50 & $01: 20$ & 0.53 & 0.00478 & 12.9 & 0.023 \\
\hline 0.03075 & 1 & 0.15 & 0.0396 & 50 & $01: 20$ & 0.54 & 0.00797 & 12.73 & 0.0307 \\
\hline 0.03075 & 1 & 0.15 & 0.0396 & 50 & $01: 20$ & 0.51 & 0.01196 & 12.6 & 0.0972 \\
\hline 0.03075 & 1 & 0.15 & 0.0396 & 50 & $01: 20$ & 0.50 & 0.0159 & 12.5 & 0.123 \\
\hline 0.03075 & 1 & 0.15 & 0.0396 & 50 & $01: 20$ & 0.62 & 0.0199 & 12.35 & 0.142 \\
\hline 0.03075 & 1 & 0.15 & 0.0396 & 50 & $01: 20$ & 0.58 & 0.0239 & 12.29 & 0.154 \\
\hline 0.03075 & 1 & 0.15 & 0.0396 & 50 & $01: 20$ & 0.52 & 0.0319 & 12.2 & 0.197 \\
\hline
\end{tabular}

*Degree of substitution (DS): Carboxymethyl derivative; **DS: Quaternized derivative

240

The effect of CHPTAC concentration $(0.00478-0.0319 \mathrm{~mol})$ on the cationization of anionic CTG was studied in terms of the effect on DS and $\mathrm{pH}$ of reaction medium (Table 1). A distinct pattern was observed for the $\mathrm{pH}$ verses CHPTAC concentration (Fig.1). As the concentration of CHPTAC increases from 0.00478 to $0.0319 \mathrm{~mol}$, the $\mathrm{pH}$ of the reaction medium decreases (12.9 to 12.2). A maximum of 0.2 DS for quaternization was achieved using 0.0319 mol of CHPTAC concentration at different reaction parameters studied. The increase in the cationic DS on increasing CHPTAC concentration may be due to the increased accessibility of the reactive groups (EPTAC) to the available alkoxide ions generated onto the galactomannan. Further, decrease in $\mathrm{pH}$ on increasing the concentration of CHPTAC may be due to utilization of available alkali with the CHPTAC and subsequently formation of EPTAC, as active species. 

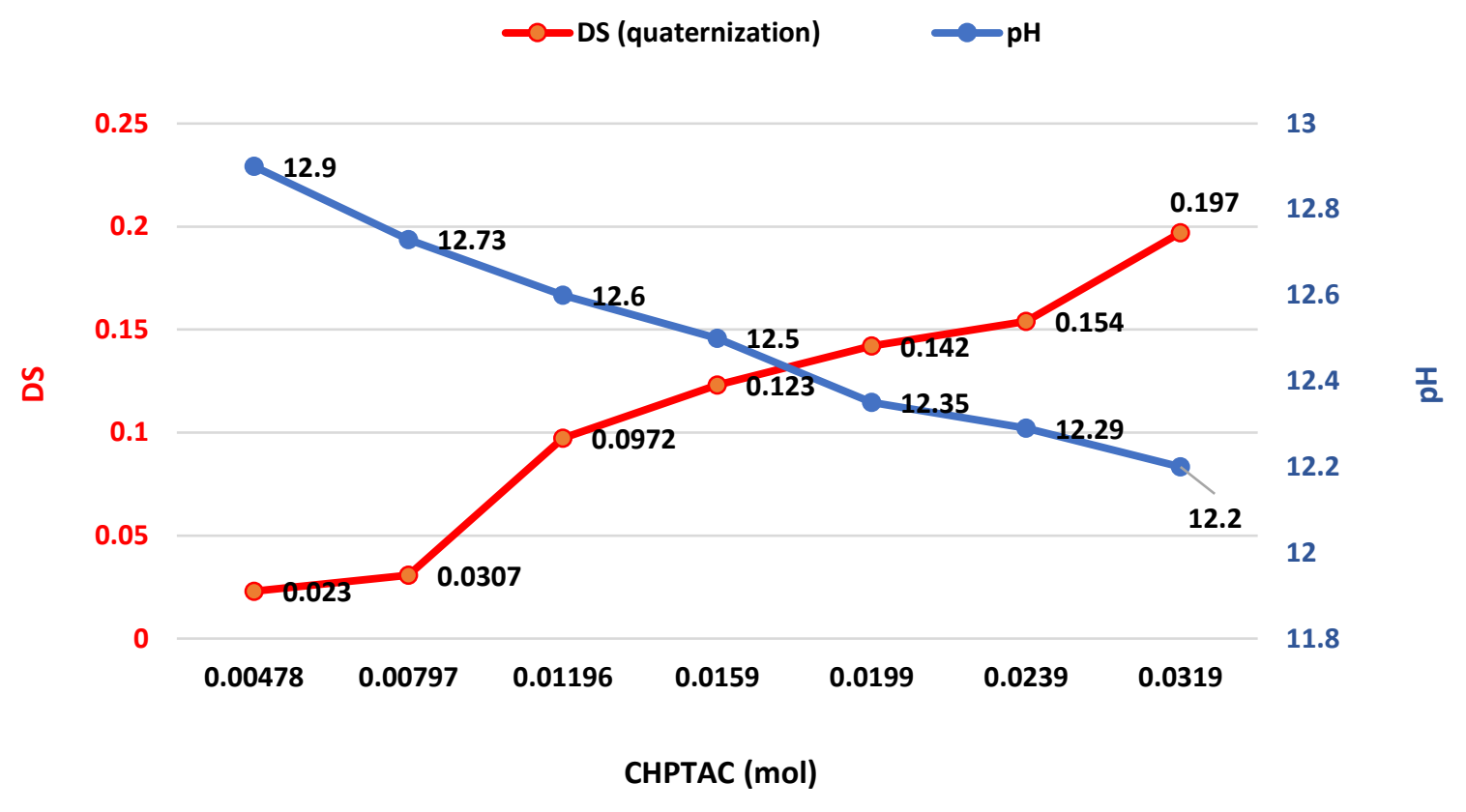

Fig. 1. Effect on DS (quaternisation) and $\mathrm{pH}$ on varying amount of CHPTAC

\subsection{Characterization}

Spectroscopic methods were used for structural analysis of CMQCTG. 1D and 2D NMR spectrum (Fig. 2) werer ecorded in order to confirm the incorporation of carboxymethyl substituent and quaternary ammonium groups onto CTG. In ${ }^{1} \mathrm{H}-\mathrm{NMR}$ spectra, corresponding to $\alpha$ - and $\beta$ - anomeric confirmers of galactose and mannose units, signals were observed in the region from 4.8 to 5.3 ppm (Bigand et al., 2011; Tako et al., 2018). The ${ }^{1} \mathrm{H}-\mathrm{NMR}$ spectrum of CTG (Fig.2a) and CMQCTG (Fig. 2b) showed characteristic chemical shifts clustered between $3.3 \mathrm{ppm}$ to $4.25 \mathrm{ppm}$ for ring protons of mannose and galactose units. The occurrence of new peak of proton at $3.07 \mathrm{ppm}$ in the spectra of CMQCTG was attributed to methyl protons $\left(\mathrm{C}-\mathrm{d},-\mathrm{CH}_{2} \mathrm{~N}\left(\mathrm{CH}_{3}\right)_{3}\right)$ of quaternary ammonium groups and another downfield substituents (Dodi et al., 2011). 


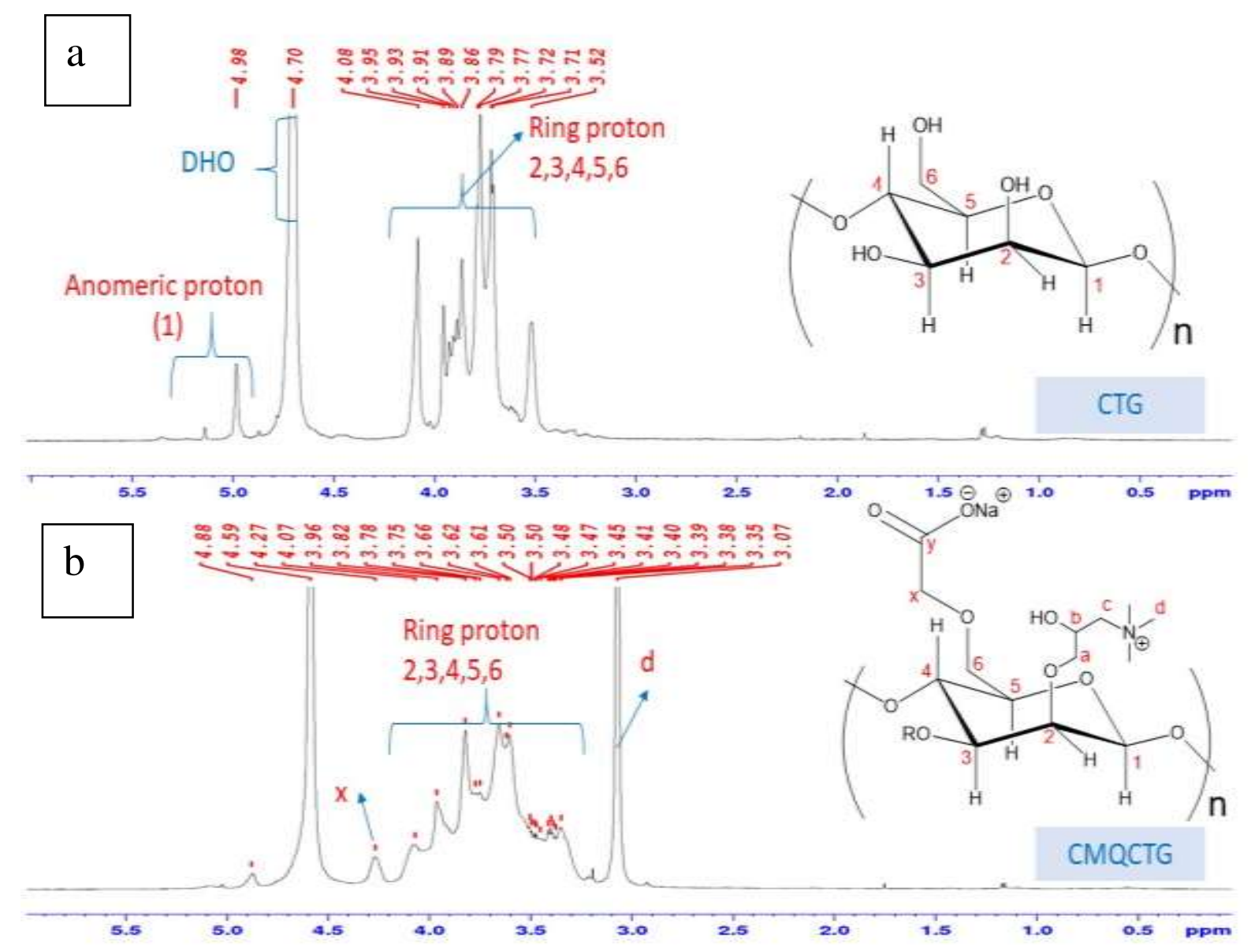



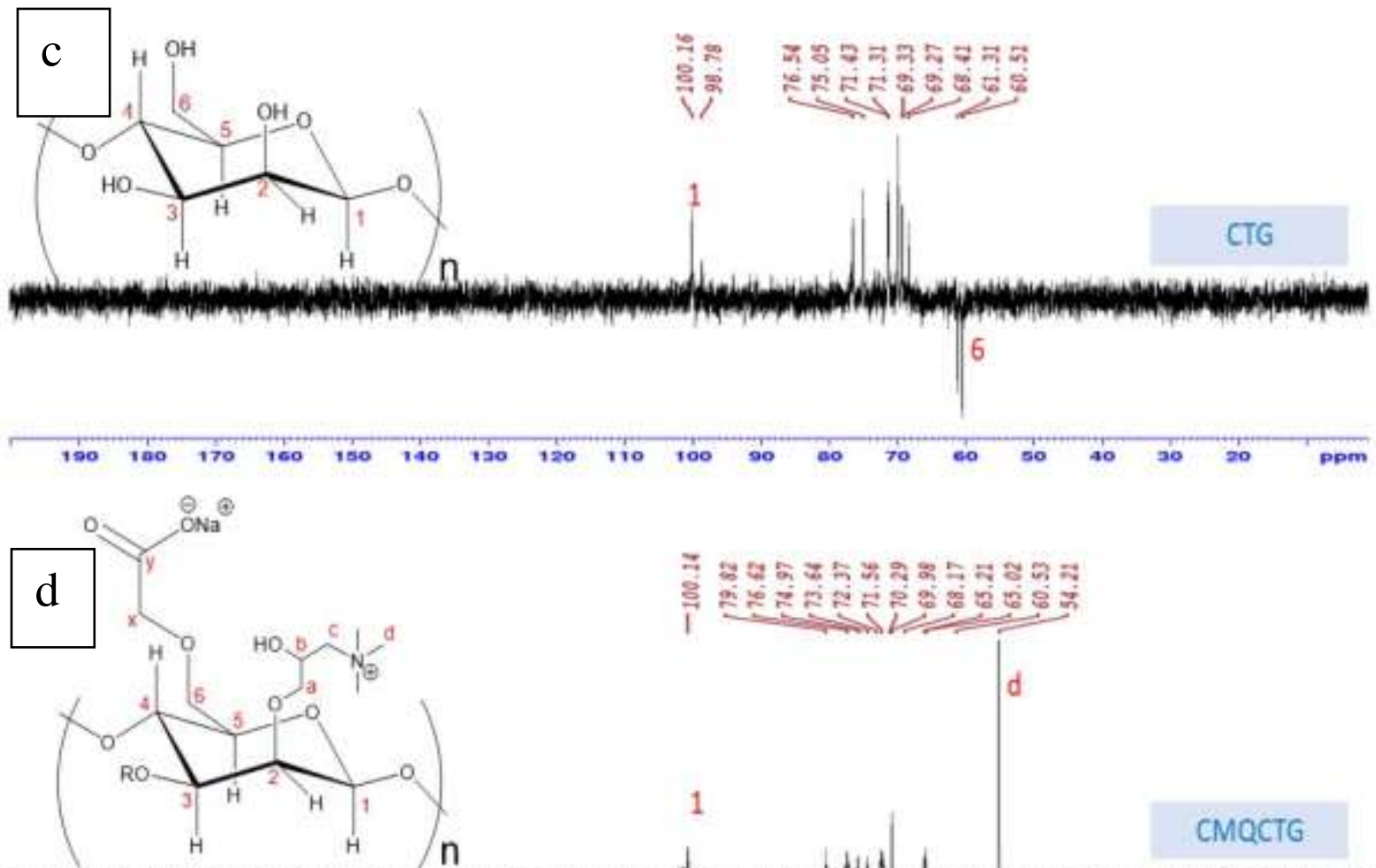

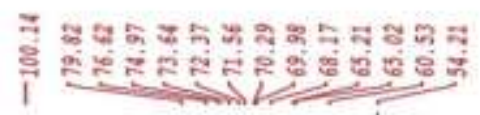

CMQCTG

How
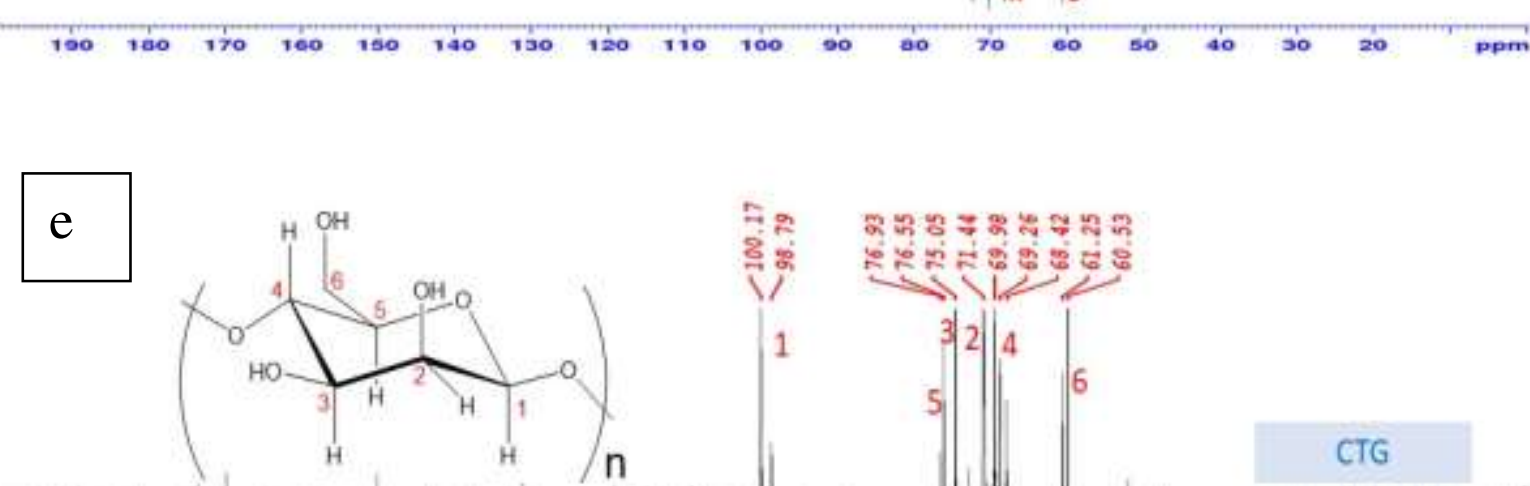

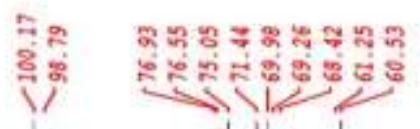

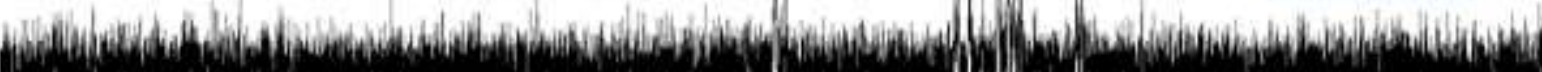

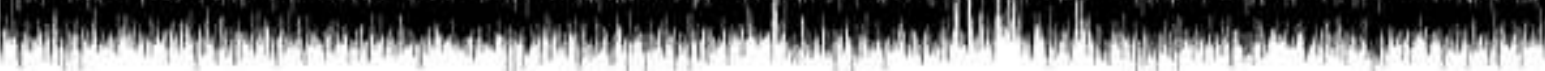

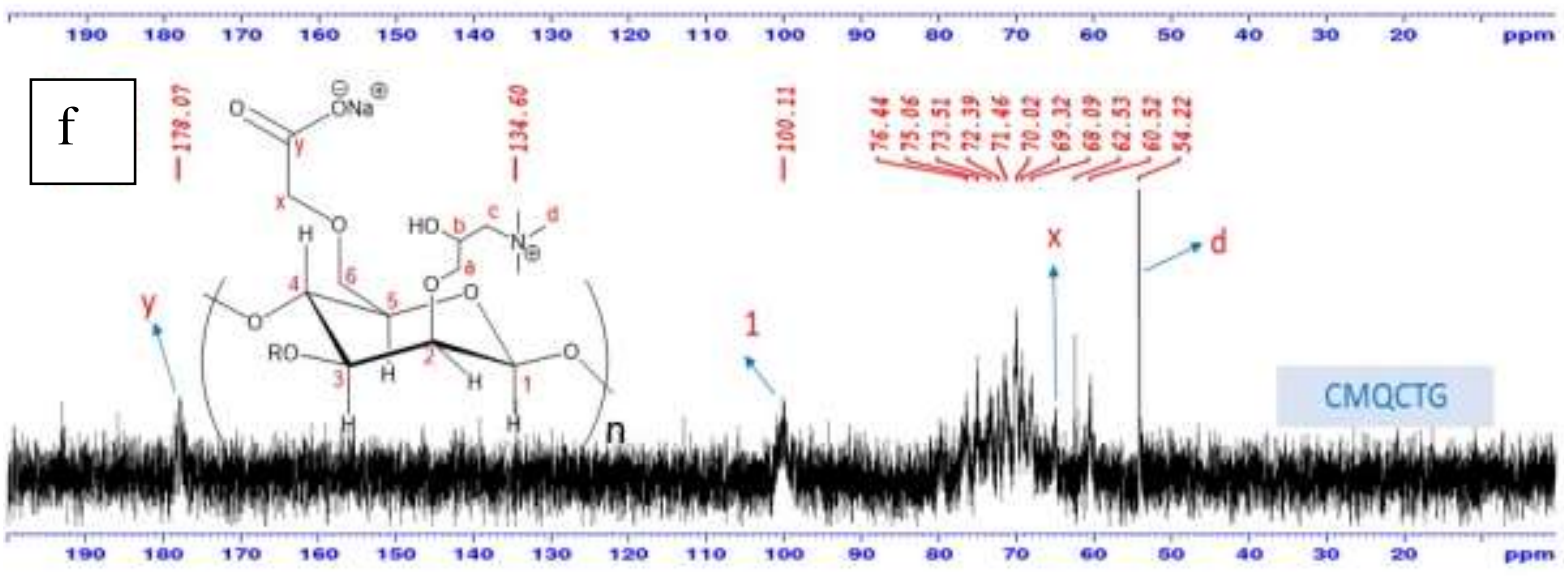



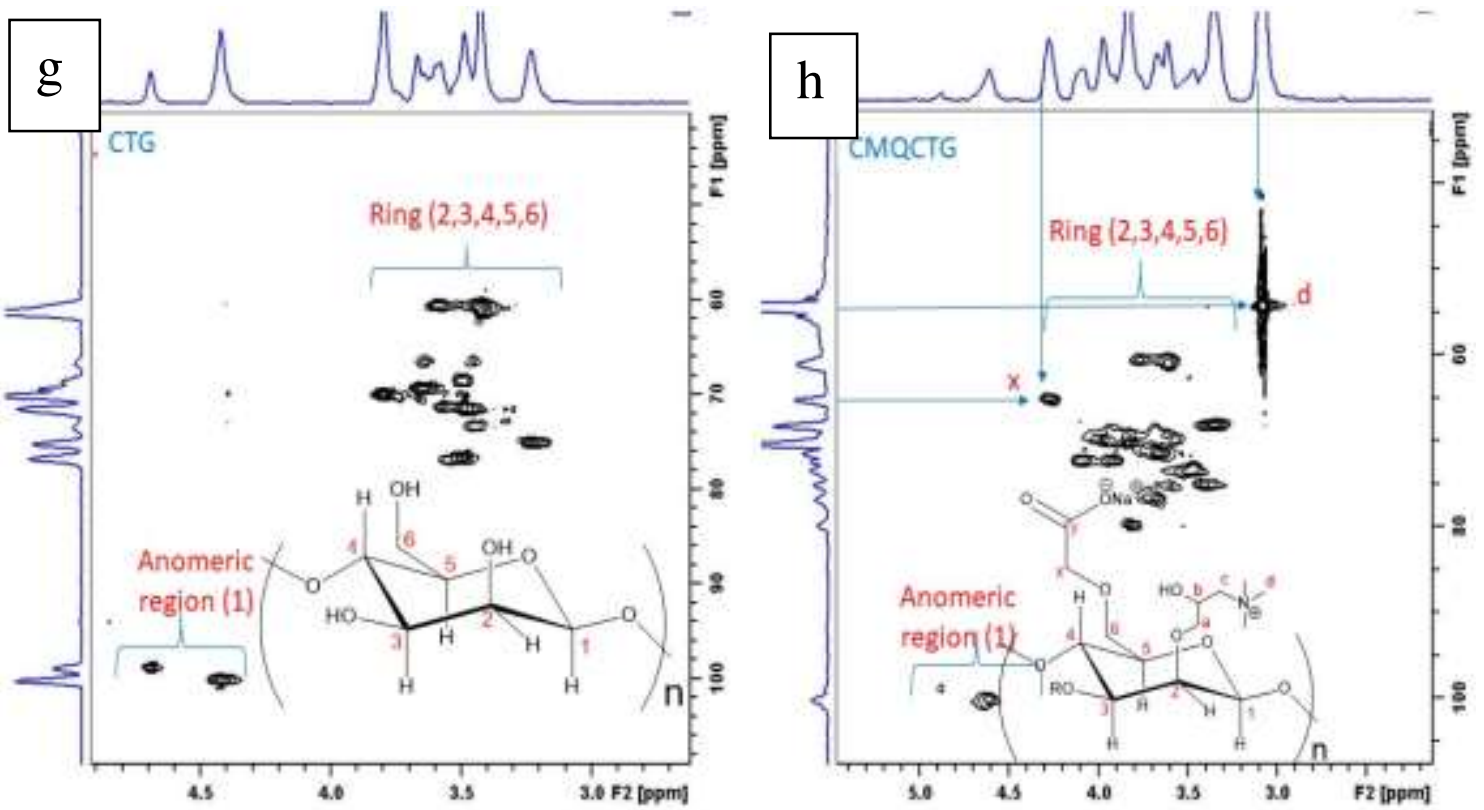

Fig. 2. NMR spectrum of CTG and CMQCTG: (a\& b) ${ }^{1} \mathrm{H}-\mathrm{NMR}$ spectrum; (c \& d) ${ }^{13} \mathrm{C}-\mathrm{NMR}$ spectrum; (e \& f) DEPT Spectrum; (g \& h) HSQC Spectrum

These two additional peaks in ${ }^{1} \mathrm{H}-\mathrm{NMR}$ of CMQCTG confirm the incorporation of quaternary ammonium and carboxymethyl substituents onto galactomannan chain. The ${ }^{13} \mathrm{C}-\mathrm{NMR}$ spectrum of CMQCTG (Fig.2d) showed three additional peaks in comparison to CTG (Fig. 2c). The prominent peak observed at $54.22 \mathrm{ppm}$ was assigned to methyl carbons ($\left.\mathrm{CH}_{2} \mathrm{~N}\left(\mathrm{CH}_{3}\right)_{3}, \mathrm{C}-\mathrm{d}\right)$ of quaternary ammonium groups and the peak for methylene carbon ($\left.\mathrm{CH}_{2} \mathrm{~N}\left(\mathrm{CH}_{3}\right)_{3}, \mathrm{C}-7\right)$ of carboxymethyl groups appeared at $68.09 \mathrm{ppm}$. The extreme downfield peak observed at 178.07 ppm can be assigned to the carboxyl (- $\left.\mathrm{COO}^{-}\right)$group at $\mathrm{C}-8$ position. Further, the negative peaks appeared at $68.12 \mathrm{ppm}$ and $60.53 \mathrm{ppm}$ in DEPT-135 NMR (Fig. 2e \& f) corroborates the presence of $\mathrm{CH}_{2}$ groups on the carboxymethyl substituents $(\mathrm{C}-7)$ and carbon at C-6 $\left(\mathrm{CH}_{2}\right)$ position respectively. In addition, the correlation peaks (absence of signals in Fig. 2g) of carbon and hydrogen (Fig. 2h) for C-7 at 4.3 and 68.09 ppm and C-d at 3.07 and $54.22 \mathrm{ppm}$ for ${ }^{1} \mathrm{H} \&{ }^{13} \mathrm{C}$-NMR respectively confirms the presence of carboxymethyl and quaternary ammonium substituents in the amphoteric derivative.

FT-IR spectra were recorded to elucidate the structure of CTG and CMQCTG (Fig.3a). The broad band from 3600 and $3000 \mathrm{~cm}^{-1}$ is attributed to $\mathrm{O}-\mathrm{H}$ stretching frequency and it is due to 
inter as well as intra molecular hydrogen bonding involving between the hydroxyl groups of the gum molecules. The band at $2919.6 \mathrm{~cm}^{-1}$ was assigned to characteristics symmetrical stretching vibrations due to the $-\mathrm{CH}_{2}$ groups (Yuen et al., 2009). In native CTG the band at $1641.3 \mathrm{~cm}^{-1}$ was attributed to scissoring of two $\mathrm{O}-\mathrm{H}$ bond of absorbed water molecule (Liu et al., 2012; Mudgil et al., 2012). The band appeared at $1025.8 \mathrm{~cm}^{-1}$ was due to the $-\mathrm{C}-\mathrm{O}-\mathrm{C}$ stretching frequency of ether bond in the ring. The two other absorption bands at $814.6 \mathrm{~cm}^{-1}$ and $875.5 \mathrm{~cm}^{-1}$ can be assigned to $\alpha$-D-galactopyranose and $\beta$-D-mannopyranose units of anomeric region respectively (Yuen et al., 2009; Figueiro et al., 2004; Prado et al., 2005). These characteristic peaks were also observed in the amphoteric derivative. In addition, four 2012), were observed in the amphoteric derivative.

Wide-angle X-ray diffractogram of native gum showed the presence of diffraction peaks at $20^{\circ} \& 38^{\circ} 2 \theta$ suggesting a semi-crystalline structure in nature (Fig. 3b). By contrast, in the XRD pattern of CMQCTG, the diffraction intensity has reduced and the peak shape switched from broad to diffuse peak indicating decrease in crystalline structure due to the incorporation of anionic and cationic groups (Wang \& Xie, 2010). The cationic and anionic interaction also prevents the molecule acquiring complete amorphous structure. This decrease in crystalline structure may also be due to the alkaline medium during the reaction leading to interruption in intermolecular hydrogen bonding and consequently destruction in the crystalline structure. On the other hand, incorporated carboxymethyl and quaternary ammonium substituents onto the galactomannan resulting in a steric effect which reduces the formation of intermolecular hydrogen bonding and consequently, the gum molecules arrange in a semi-crystalline structure (Zhang et al., 2013). 

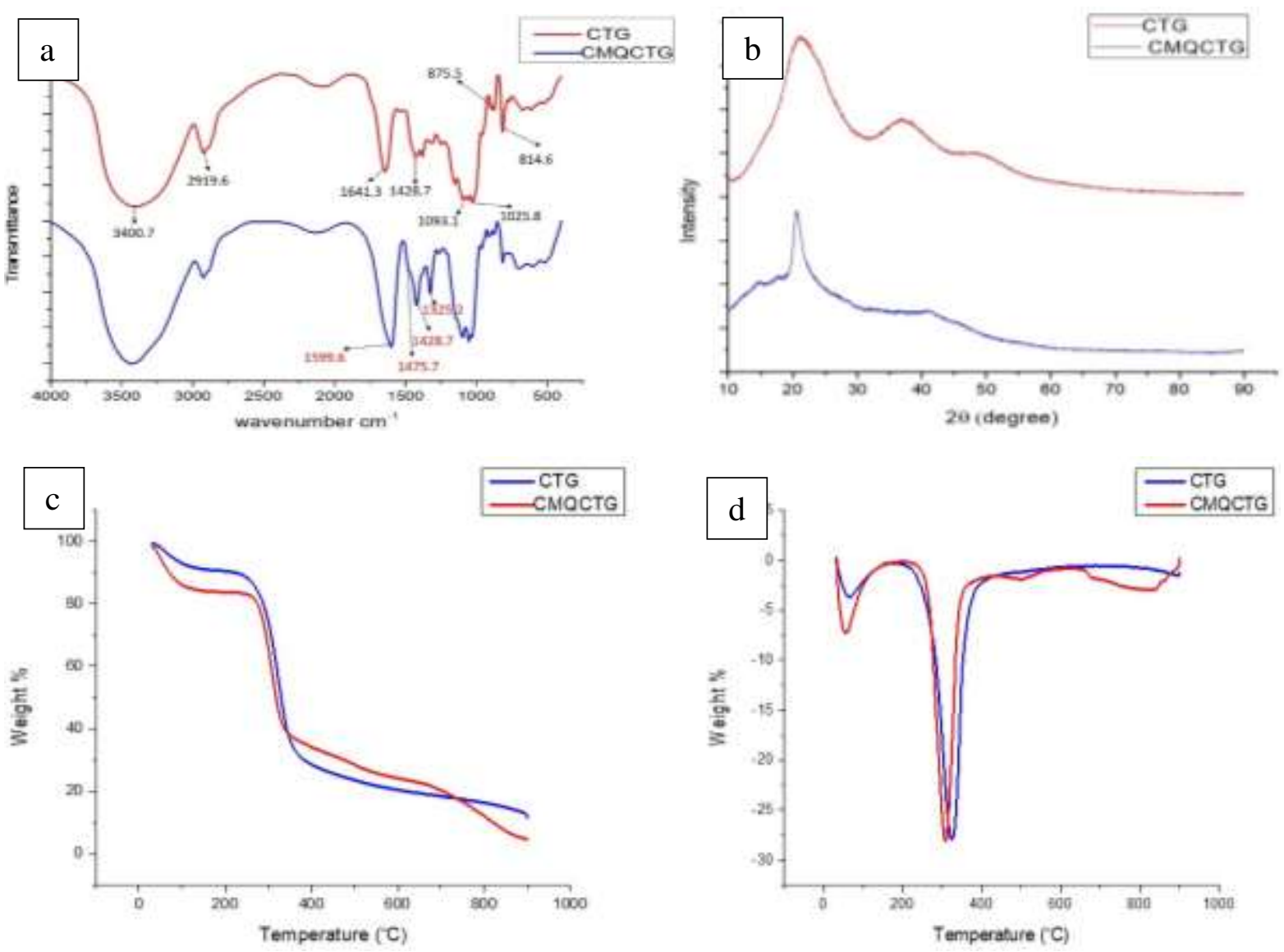

315

Fig.3. (a) FT-IR spectra of CTG \& CMQCTG (b) XRD of CTG and CMQCTG (c) TGA of

\section{CTG \& CMQCTG (d) DTG of CTG \& CMQCTG}

The results for TG and DTG for CTG and CMQCTG derivatives are presented in Fig. 3c \&

$3 \mathrm{~d}$ which provides vital information about the thermal stability of polymeric material, such thermophysical information is of great use for industrial applications of polymer. The CTG and CMQCTG showed two stage weight losses up to $800^{\circ} \mathrm{C}$. The first weight loss is due to the moisture content up to $125^{\circ} \mathrm{C}$. The second weight loss is due to the decomposition of polysaccharide, water is main product of decomposition below $350^{\circ} \mathrm{C}$. The $\mathrm{CTG}$ began to decompose at $250^{\circ} \mathrm{C}$, and underwent $65 \%$ weight loss at $380^{\circ} \mathrm{C}$. The studies indicate that the maximum degradation occurred within the range $240-410^{\circ} \mathrm{C}$ and the peak as indicated by the DTG (DTG max $)\left(\right.$ Fig.3d) was at $335^{\circ} \mathrm{C}$. Further heating from 450 to $800^{\circ} \mathrm{C}$ resulted in carbonization and ash formation. In case of CMQCTG, maximum degradation occurs within the range of 220 to $390^{\circ} \mathrm{C}$ with $45 \%$ of mass loss and the peak indicated by DTG (DTG $\max$ ) 
was at $315^{\circ} \mathrm{C}$. There is very small difference in the final decomposition temperature for CTG \& CMQCTG but the percentage mass loss for CTG is greater than the CMQCTG. The lesser percentage mass loss in case of CMQCTG (45\%) in comparison to CTG (65\%) indicating the better thermal stability of amphoteric derivative. The initial decomposition temperature of CMQCTG is lower than the initial decomposition temperature of the CTG. This may be due to the substitution of the hydroxyl groups onto galactomannan chain with carboxymethyl and quaternized ammonium groups which results in better thermal stability ( $\mathrm{Li}$ et al., 2010). whereas the surface morphology of CMQCTG (Fig. 4 b) altered markedly due to the insertion of cationic and anionic moiety onto CTG.

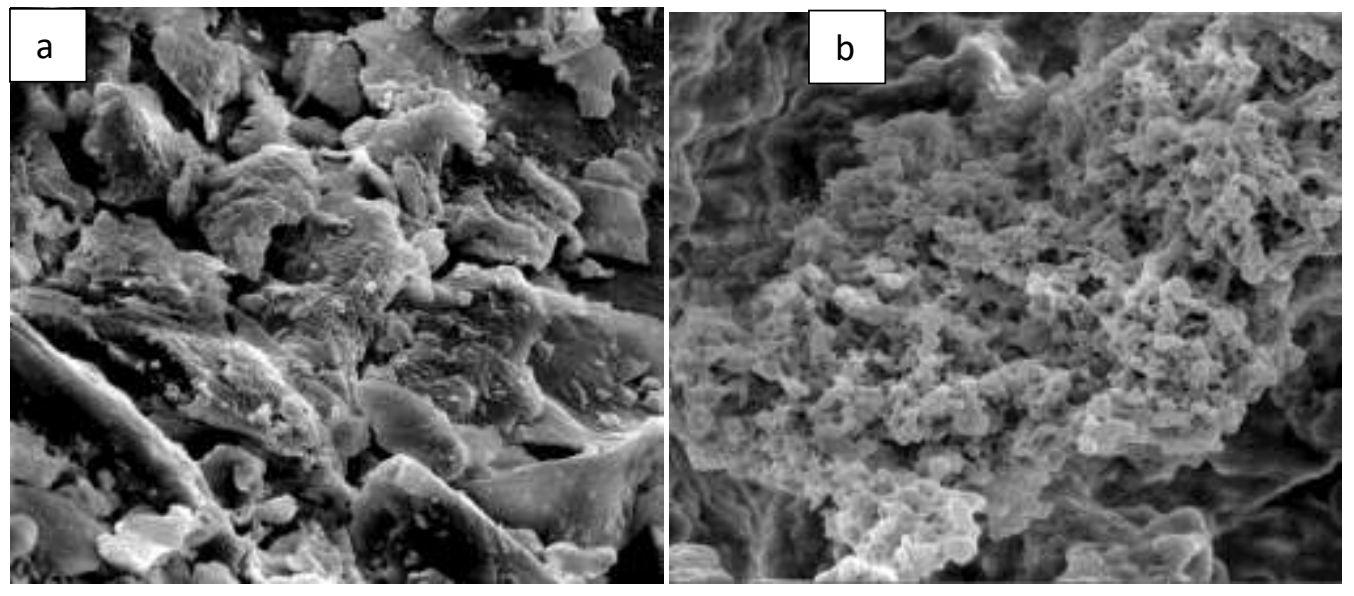

Fig. 4. (a) FESEM image of (a) CTG and (b) CMQCTG

Fig. $4 \mathrm{~b}$ shows the surface of CMQCTG which is completely disintegrated into a porous and highly rough surface with devoid of well-defined edges. The incorporation of cationic and anionic moieties disintegrates the particle shape and size consequently increasing the surface roughness. In addition, the changes in the surface morphology of the CTG may also be due to the increased cationic and anionic interaction and columbic repulsion in the molecular 
hydrogen bonding. The chemical analysis and thorough spectroscopic studies showed that

349 CTG was successfully derivatized into amphoteric derivative.

\subsection{Adsorption study of malachite green and congored dyes by amphoteric derivative}

351 The removal of Malachite Green (MG) and Congo red (CR) dyes was performed considering 352 four factors viz. cationic DS, adsorbent amount, temperature, and contact time for optimization process. The effect of each parameter was assessed using Taguchi's experimental design comprising of a total of 9 experiments (Table 2) in terms of response values as percentage and signal to noise $(S / N)$ ratios.

The $S / N$ ratio was used to assess the quality characteristics of the product ( $\mathrm{Li}$ et al., 2016; Tutar et al., 2014; Yang \&Tarng, 1998). The highest $S / N$ ratio signifies the optimum level for each factor and contributes to the maximum percentage. $S / N$ ratio may be obtained by using equation 5 .

$$
\frac{S}{N} \text { ratio }=-10 \log _{10}(M S D)
$$

Where, MSD denotes the mean square deviation for output characteristic, and may be determined as (Eqn. 6).

$M S D=\frac{1}{n} \sum_{i=1}^{n} 1 / y i^{2}$

Here, $\mathrm{n}$ represents the number of repetitions in the orthogonal array for the experimental design, and yi represents quality characteristic of the ith experiment. The average $S / N$ ratio of each experiment for each factor is given in Fig.5.

Dyes comprising of positive and negative charge and their on the dual derivative is based on the ion exchange mechanism (Bouaziz et al., 2017), and indulge by the electrostatic attraction between amphoteric groups and the cationic and anionic dye molecules, $(\mathrm{MG})^{+}$and $(\mathrm{CR})^{-}$. 
the positively charged malachite green molecules. In case of anionic dye $(\mathrm{CR})^{-}$there is an electrostatic force of attraction between the negatively charged surface of CR and positively charged quaternary ammonium groups present on the CMQCTG. This electrostatic force of attraction between the dye molecules and the CMQCTG results into the removal of dye from water by settling/precipitation on the surface.

\subsubsection{Effect of amphoteric derivative on adsorption capacity of dyes}

The effect of amphoteric derivative on the dyes was studied with respect to $S / N$ ratio which is directly proportional to percentage of dyes. In the present study the anionic DS (0.5) was kept constant and the cationic DS was varied $(0.012,0.123, \& 0.197)$. Increasing the cationic DS, there is not any perceivable effect due to the presence of unvarying anionic charge (DS 0.5) on the CMQCTG which form the bond with the cationic surface of MG dye, however, the $S / N$ ratio increases with increase in cationic DS constantly leading to increase in adsorption of CR dye. The product with cationic DS (0.197) showed maximum percentage or $S / N$ ratio for both MG \& CR dye.

\subsubsection{Effect of the amount of amphoteric derivative on adsorption capacity}

The study of the of MG and CR on the CMQCTG was performed at a dose of 10 to $50 \mathrm{mg}$ in the dye solution (25ppm) with respect to $S / N$ ratio obtained from the Taguchi L'9 statistical design. The result shown in Fig.5, and 6 reveals that on increasing the amount of CMQCTG the adsorption of dyes ( $\mathrm{MG}$ and $\mathrm{CR}$ ) increases. The increase in adsorption of dyes may be due to the presence of additional sites for adsorption on increasing the concentration of the amphoteric derivative. A dose of $50 \mathrm{mg}$ of absorbent showed maximum adsorption for the dyes.

\subsubsection{Effect of temperature on adsorption capacity}


The effect of temperature on the adsorption study with respect to $S / N$ ratio was studied in the range of $25-45^{\circ} \mathrm{C}$. On increasing the temperature, the $S / N$ ratio decreased in the case of $\mathrm{MG}$ leading to a decrease in adsorption percentage. Whereas, in case of $\mathrm{CR}$ the maximum adsorption was observed at $35^{\circ} \mathrm{C}$ and thereafter it decreased. Therefore, at a temperature of $25^{\circ} \mathrm{C}$ and $35^{\circ} \mathrm{C}$ maximum adsorption was observed for $\mathrm{MG}$ and $\mathrm{CR}$ dyes respectively.

Table 2. Matrix layout of Taguchi L'9 and the adsorption percentage of MG and CR

\begin{tabular}{|c|c|c|c|c|c|c|}
\hline \multirow{2}{*}{ Run } & \multicolumn{4}{|c|}{ Factor } & \multicolumn{2}{c|}{ Results } \\
\cline { 2 - 7 } & Cationic DS & $\begin{array}{c}\text { Dose amount } \\
(\mathrm{mg})\end{array}$ & $\begin{array}{c}\text { Temperature } \\
\left({ }^{\circ} \mathrm{C}\right)\end{array}$ & $\begin{array}{c}\text { Time } \\
(\mathrm{min})\end{array}$ & $\% \mathrm{MG}$ & $\%$ CR \\
\hline 1 & 0.197 & 50 & 35 & 60 & 63.20 & 16.88 \\
\hline 2 & 0.123 & 10 & 35 & 120 & 51.20 & 7.00 \\
\hline 3 & 0.023 & 25 & 35 & 90 & 50.60 & 4.56 \\
\hline 4 & 0.023 & 10 & 25 & 60 & 53.40 & 3.32 \\
\hline 5 & 0.197 & 10 & 45 & 90 & 48.80 & 10.48 \\
\hline 6 & 0.123 & 50 & 25 & 90 & 60.00 & 4.56 \\
\hline 7 & 0.023 & 50 & 45 & 120 & 72.60 & 3.76 \\
\hline 8 & 0.123 & 25 & 45 & 60 & 56.60 & 3.12 \\
\hline 9 & 0.197 & 25 & 25 & 120 & 66.00 & 12.80 \\
\hline
\end{tabular}

401

402

\subsubsection{Effect of contact time on adsorption capacity}

The effect of contact time of CMQCTG and the dyes was studied with respect to $S / N$ ratio using statistical design. The results reveal that on increasing the duration of time (60-120 min) the adsorption of dyes increased. Generally, it is a surface phenomenon so as the time increases the maximum active sites present on the dye surface gets attached to the adsorbent time for the maximum removal of MG \& CR (Fig. 6). 

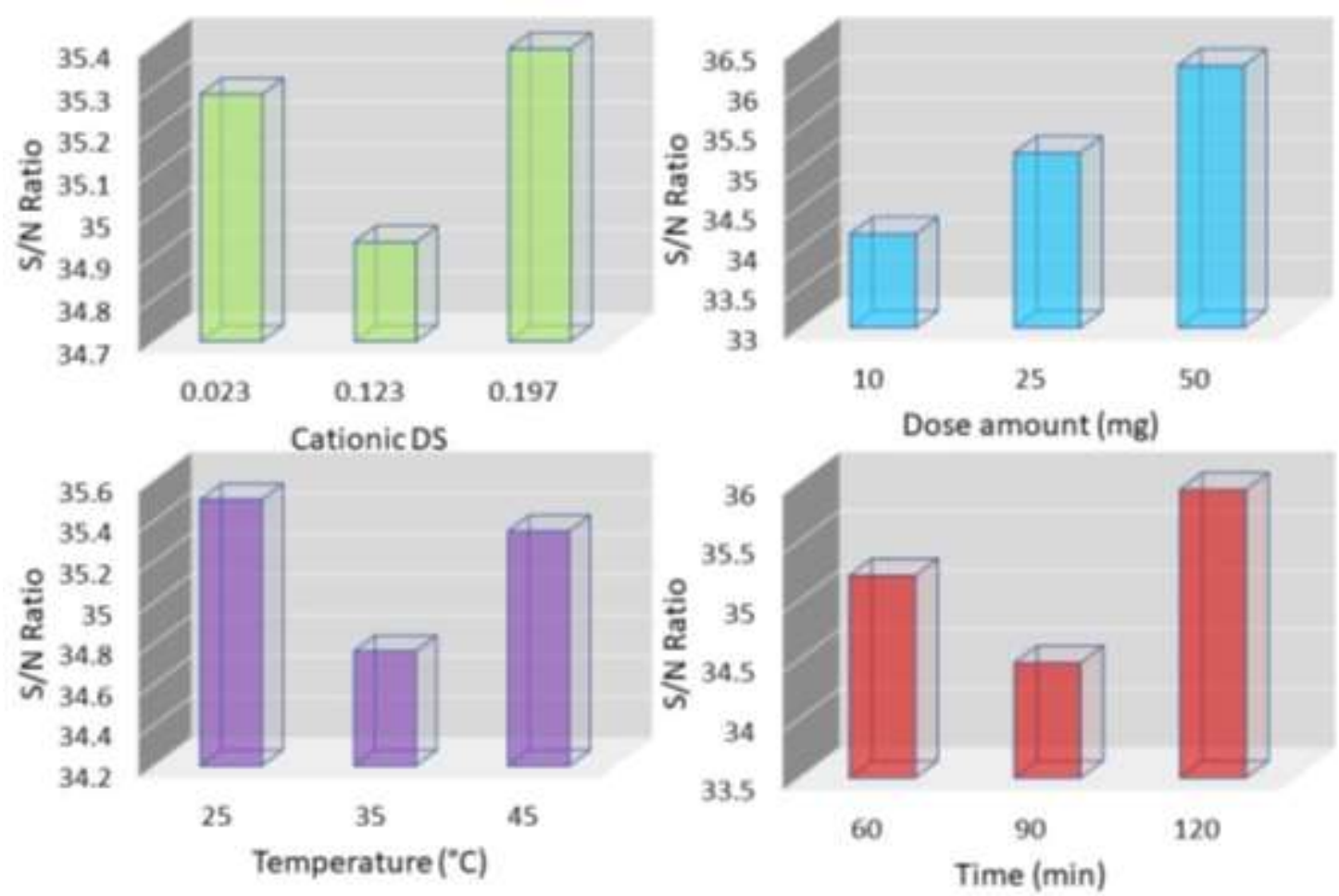

411 Fig. 5. Effect of different parameters on Malachite Green dyes with respect to $S / N$ ratio
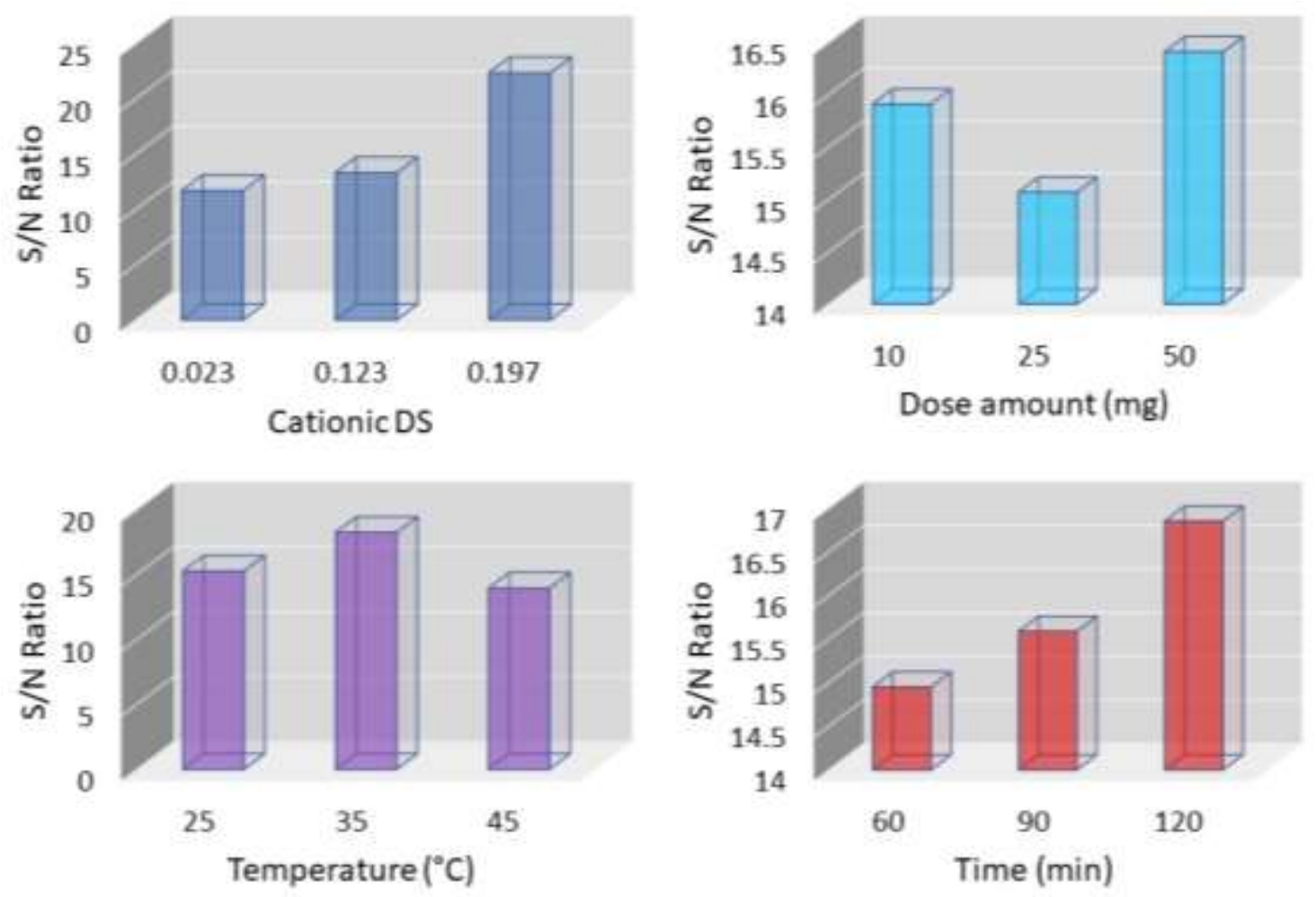

413 Fig.6. Effect of different parameters on Congo Red dyes with respect to $S / N$ ratio 
The experimental results (Fig. 5 and 6) suggest that these factors at the optimum levels

415

416

417

\begin{tabular}{|c|c|c|c|}
\hline Adsorbents & $\begin{array}{l}\text { Maximum } \\
\text { capacity \% }\end{array}$ & Dye investigated & References \\
\hline Amphoteric Cassia tora gum & 73 & Malachite green & Present work \\
\hline Amphoteric Cassia tora gum & 17 & Congo red & Present work \\
\hline Luffa cylindrica fibres & 4.7 & Methylene blue & $\begin{array}{c}\text { Cengiz } \\
\text { \&Cavas, } \\
2008 \\
\end{array}$ \\
\hline Almond gum & 19.6 & Malachite green & $\begin{array}{c}\text { Bouaziz et } \\
\text { al., } 2017\end{array}$ \\
\hline Grass waste & 45.7 & Methylene blue & $\begin{array}{c}\text { Hameed, } \\
2009\end{array}$ \\
\hline Coffee husks & 9.01 & Malachite green & Baek, 2010 \\
\hline Sun flower seed hull & 9.2 & Methyl violet & $\begin{array}{c}\text { Hameed, } \\
2008\end{array}$ \\
\hline Broad bean peels & 19.27 & Malachite green & $\begin{array}{c}\text { Hameed \& } \\
\text { El-Khaiary, } \\
2008\end{array}$ \\
\hline
\end{tabular}




\begin{tabular}{|c|c|c|c|}
\hline Crosslinked Chitosan beads & 9.35 & Malachite green & Chiou, 2004 \\
\hline Untreated guava leaves & 29.5 & Methylene blue & $\begin{array}{c}\text { Ponnusami } \\
\text { et al., 2008 }\end{array}$ \\
\hline Solid waste of soda ash plant & 66.7 & Reactive red 231 & Şener, 2008 \\
\hline
\end{tabular}

424

\subsection{Flocculation characteristics}

The flocculation results of the amphoteric CMQCTG samples with cationic DS values $(0.12$, 0.197) on kaolin suspension were measured in terms of the absorbance of the supernatant liquid and the results are shown in Fig.7. It was observed that the product with higher DS (0.197) is a better flocculant in kaolin suspension than the product with lower DS (0.12) in all concentrations. The effect was probably due to the electrostatic force of attraction between the cationic quaternary ammonium groups present on the CMQCTG derivative and the negatively charged particles of the kaolin suspension via bridging and charge neutralization process (Cengi \& Cavas, 2008). The present study shows that on increasing the concentration of cationic samples from 10 to $50 \mathrm{ppm}$ the absorbance increases, resulting in an increase in the turbidity of the suspension consequently decreasing the flocculation efficiency. This effect may be due to the surface charge of kaolin became positive due to the absorbance of cationic gum; thus, on increasing the concentration of flocculant doses the phenomenon of bridging becomes insignificant due to the higher electric positive charge which leads to mutual electrostatic repulsion consequences redispersion of the aggregated particles. The CMQCTG having high DS (0.197) shows better flocculation results at a minimum concentration $(10 \mathrm{ppm})$ in comparison to $0.12 \mathrm{DS}$. From the aforementioned results, it was found that the flocculation performance of CMQCTG is significantly enhanced on 
443 introduction of cationic groups with high DS and can be used potentially as an efficient 444 flocculant in wastewater treatments.

445

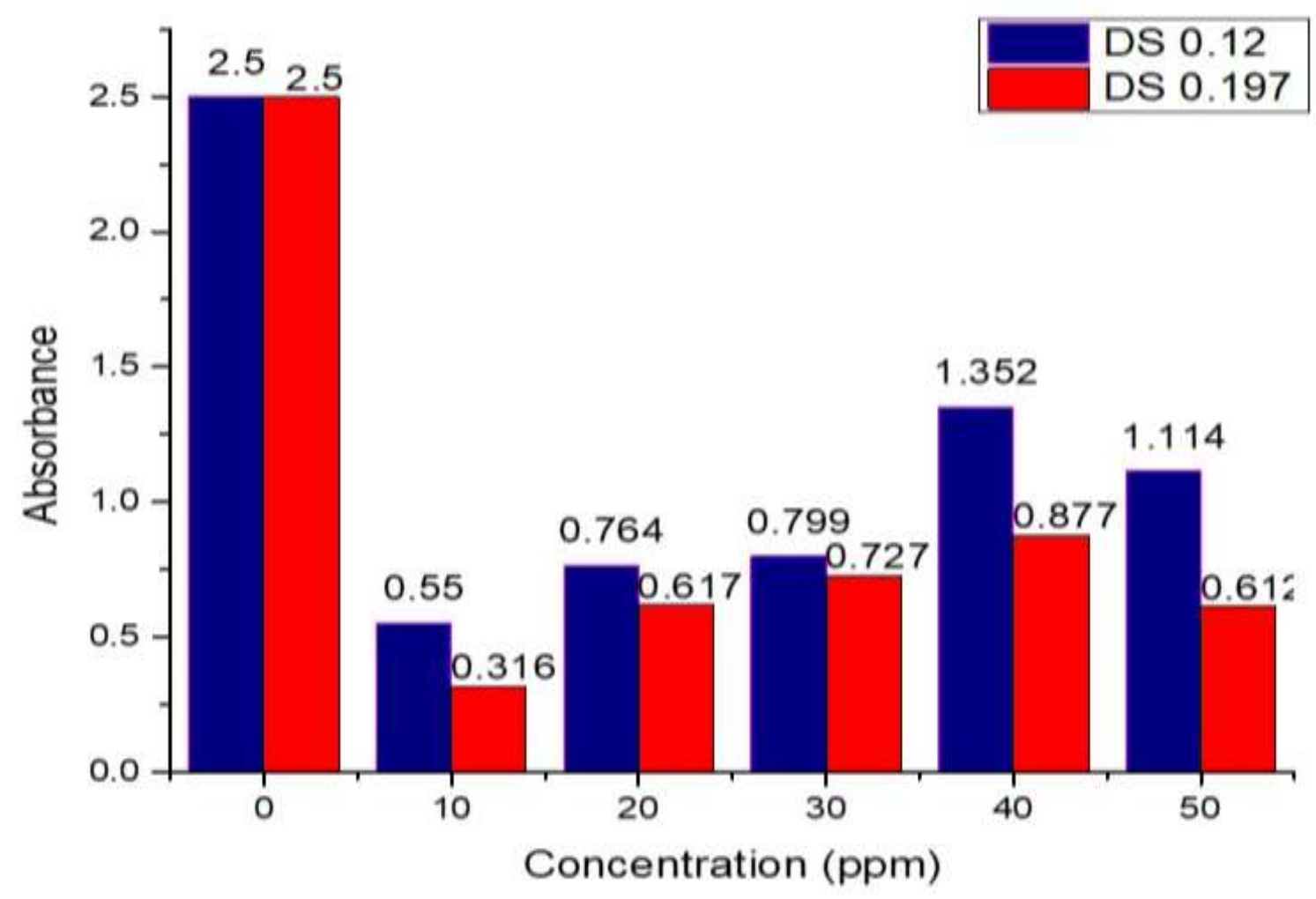

Fig. 7. Flocculation performance of CMQCTG

\section{Conclusion}

A novel biopolymeric, amphoteric derivative of $C$. tora gum was synthesized under heterogeneous conditions using monochloroacetic acid and 3-chloro-2hydroxypropyltrimethyl ammonium chloride. The derivative was thoroughly characterized by spectroscopic techniques and investigated for its function and applicability in waste water treatments for cationic (MG) and anionic (CR) dyes. A systematic statistical design i.e.,

454 Taguchi' L'9 was used to conduct the experiment for optimization of dye process viz. 455 adsorbent dosage, temperature, and time. The results reveal that $73 \%$ of MG and $17 \%$ of CR 456 dye may be efficiently removed under stipulated conditions. The flocculation results 457 demonstrated that the CMQCTG products have good flocculation efficiency over at 
minimum concentration of dosages (10 ppm), and thus, it may be utilized as flocculant for wastewater treatment. The optimized reaction conditions for production of amphoteric derivative having DS of 0.52 and 0.197 for carboxymethylation and quaternization

461 respectively were achieved using $0.0396 \mathrm{~mol} \mathrm{MCA} \mathrm{,} 0.15 \mathrm{~mol} \mathrm{NaOH}$, time 60min, 1:20

462 gum:solvent (80:20:: IPA: $\left.\mathrm{H}_{2} \mathrm{O}\right)$ ratio at $50^{\circ} \mathrm{C}$ for 0.03075 , mol of $\mathrm{CTG}$ and 0.0319 mol

463 CHPTAC, reaction time 60 and $240 \mathrm{~min}$ for carboxymethylation and quaternization 464 respectivley. In conclusion, it may be deduced that the amphoteric derivative of $C$. tora gum 465 is environmentally friendly biopolymer which has promising potential for removal of both 466 cationic and anionic dyes from aqueous solutions and also as a potential flocculant for 467 wastewater treatment.

\section{Acknowledgments}

469 The authors are grateful to the Director, Forest Research Institute (FRI), Dehradun for 470 providing laboratory facilities. Authors gratefully acknowledge Sophisticated Analytical 471 Instrumental Facility (SAIF), Panjab University, Chandigarh for recording spectral data.

\section{Conflict of Interest}

473 The authors declare that they have no conflicts of interest to declare that are relevant to the 474 content of this article. 
References:

479

480

481

482

483

484

485

486

487

488

489

490

491

492

493

494

495

496

497

498

499

500

Ahmad R, Kumar R (2010) Adsorption Studies of hazardous malachite green onto treated $\begin{array}{lllll}\text { ginger waste. } & \mathrm{J} & \text { Environ } & \text { Manage } & \text { 91: 1032-1038. DOI: }\end{array}$ 10.1016/j.jenvman.2009.12.016

ASTM D1439-15 (2015) Standard Test Methods for Sodium Carboxymethylcellulose ASTM International, West Conshohocken PA. www.astm.org

Baek MH, Ijagbemi CO, Se-Jin O, \& Kim DS (2010) Removal of Malachite Green from aqueous solution using degreased coffee bean. J Hazard Mater 176(1-3): 820-828. DOI: 10.1016/j.jhazmat.2009.11.110

Banerjee C, Ghosh S, Sen G, Mishra S, Shukla P, Bandopadhyay R (2013) Study of algal biomass harvesting using cationic guar gum from the natural plant source as flocculant. Carbohydr Polym 92(1): 675-681. DOI: 10.1016/j.carbpol.2012.09.022

Bekci Z, Özveri C, Seki Y, Yurdakoç K (2008) Sorption of malachite green on chitosan bead. J Hazard Mater 154: 254-261. DOI: 10.1016/j.jhazmat.2007.10.021

Bigand V, Pinel C, Perez DDS, Rataboul F, Huber P, Petit-Conil M (2011) Cationisation of galactomannan and xylan hemicelluloses. Carbohydr Polym 85(1): 138-148. DOI: 10.1016/j.carbpol.2011.02.005

Blackburn RS (2004) Natural polysaccharides and their interactions with dye molecules: applications in effluent treatment. Environ Sci Technol 38(18): 4905-4909. DOI: $10.1021 / \mathrm{es} 049972 \mathrm{n}$

Bouaziz F, Koubaa M, Kallel F, Ghorbel RE, Chaabouni SE (2017) Adsorptive removal of malachite green from aqueous solutions by almond gum: kinetic study and equilibrium isotherms. Int J Biol Macromol 105: 56-65. DOI: 10.1016/j.ijbiomac.2017.06.106 

of malachite green from aqueous solutions by almond gum: kinetic study and equilibrium isotherms. Int J Biol Macromol 105: 56-65. DOI: 10.1016/j.ijbiomac.2017.06.106

Bratby J (1980) Coagulation and flocculation. Uplands: Croydon England.

Cengiz S, \&Cavas L (2008) Removal of methylene blue by invasive marine seaweed:

Caulerpa racemosa var. cylindracea. Bioresour Technol 99(7): 2357-2363. DOI: 10.1016/j.biortech.2007.05.011

Chen H, Xu H, Heinze TM, Cerniglia CE (2009) Decolorization of water and oil-soluble azo dyes by Lactobacillus acidophilus and Lactobacillus fermentum. J Ind Microbiol Biotechnol 36(12): 1459. DOI: 10.1007/s10295-009-0633-9

Chiou MS, Ho PY, \& Li HY (2004) Adsorption of anionic dyes in acid solutions using chemically cross-linked chitosan beads. Dyes and pigments 60(1): 69-84. DOI: $10.1016 / \mathrm{S} 0143-7208(03) 00140-2$

Cripps C, Bumpus JA, Aust SD (1990) Biodegradation of azo and heterocyclic dyes by Phanerochaete chrysosporium. Appl Environ Microbiol 56(4): 1114-1118.

Culp SJ, Beland FA (1996) Malachite green: a toxicological review. J Am Coll Toxicol 15(3): 219-238. DOI: 10.3109\%2F10915819609008715

Dodi G, Hritcu D, Popa MI (2011) Carboxymethylation of guar gum: synthesis and characterization. Cellul Chem Technol 45(3): 171.

Figueiro SD, Góes JC, Moreira RA, Sombra ASB (2004) On the physico-chemical and dielectric properties of glutaraldehyde crosslinked galactomannan-collagen films. CarbohydrPolym 56(3): 313-320. DOI: 10.1016/j.carbpol.2004.01.011 

Gharbani P, Tabatabaii SM, Mehrizad A (2008) Removal of Congo red from textile wastewater by ozonation. Int $\quad \mathrm{J}$ Environ $\quad$ Sci Technol 5(4): 495-500. DOI: 10.1007/BF03326046

Gong H, Liu M, Chen J, Han F, Gao C, Zhang B (2012) Synthesis and characterization of carboxymethyl guar gum and rheological properties of its solutions. Carbohydr Polym 88(3): 1015-1022. DOI: 10.1016/j.carbpol.2012.01.057

Grant SB, Saphores JD, Feldman DL, Hamilton AJ, Fletcher TD, Cook PL, Deletic A (2012) Taking the "waste" out of "wastewater" for human water security and ecosystem sustainability. Science 337(6095): 681-686. DOI: 10.1126/science.1216852

Gupta VK (2009) Application of low-cost adsorbents for dye removal-a review. J Environ Manage 90(8): 2313-2342. DOI: 10.1016/j.jenvman.2008.11.017

Hallagan JB, La Du BN, Pariza MW, Putnam JM \&Borzelleca JF (1997) Assessment of Cassia gum. Food Chem Toxicol 35(6): 625-632. DOI: 10.1016/S02786915(97)00018-5

Hameed BH (2008) Equilibrium and kinetic studies of methyl violet sorption by agricultural waste. J Hazard Mater 154: 204-212. DOI: 10.1016/j.jhazmat.2007.10.010 Hameed BH (2009) Grass waste: A novel sorbent for the removal of basic dye from aqueous solution. J Hazard Mater 166(1): 233-238. DOI: 10.1016/j.jhazmat.2008.11.019 

induced tight ultrafiltration (UF) hollow fiber membranes for effective removal of textile dyes. Environ Sci Technol 51(24): 14254-14261. DOI: 10.1021/acs.est.7b05340

Heinze T, Haack V, Rensing S (2004) Starch derivatives of high degree of functionalization. 7. Preparation of cationic 2-hydroxypropyltrimethylammonium chloride starches. Starch-Stärke, 56(7): 288-296. DOI: 10.1002/star.200300243

Heinze T, Koschella A (2005) Carboxymethyl ethers of cellulose and starch-a review. In Macromolecular Symposia March, (Vol. 223, No. 1, pp. 13-40). Weinheim: WILEY-VCH Verlag. DOI: 10.1002/masy.200550502.

Horng JY, Huang SD (1993) Removal of organic dye (direct blue) from synthetic wastewater by adsorptive bubble separation techniques. Environ Sci Technol 27(6): 11691175. DOI: $10.1021 / \mathrm{es} 00043 \mathrm{a} 017$

Huang G, Chen X, Huang H (2016) Chemical modifications and biological activities of polysaccharides. Curr Drug Targets 17(15): 1799-1803.

Karadag D, Tok S, Akgul E, Ulucan K, Evden H, Kaya MA (2006) Combining and coagulation for the treatment of azo and anthraquinone dyes from aqueous solution. Ind Eng Chem Res 45(11): 3969-3973. DOI: 10.1021/ie060164+

Kolya H, Tripathy T (2013) Hydroxyethyl Starch-g-Poly-(N, N-dimethylacrylamide-coacrylic acid): An efficient dye removing agent. Eur Polym J 49(12): 4265-4275. DOI: 10.1016/j.eurpolymj.2013.10.012 

the optimization of swimming capability for robotic fish. Int J Adv Robot Syst 13(3): 102. DOI: $10.5772 \% 2 \mathrm{~F} 64039$

Li X, Gao WY, Huang LJ, Wang YL, Huang LQ, Liu CX (2010) Preparation and physicochemical properties of carboxymethyl Fritillaria ussuriensis Maxim. starches. CarbohydrPolym 80(3): 768-773. DOI: 10.1016/j.carbpol.2009.12.025.

Liu J, Ming J, Li W, Zhao G (2012) Synthesis, characterisation and in vitro digestibility of carboxymethyl potato starch rapidly prepared with microwave-assistance. Food Chem 133(4): 1196-1205. DOI: 10.1016/j.foodchem.2011.05.061 characterization of partially hydrolyzed guar gum. Int J BiolMacromol 50(4): 1035-1039. DOI: 10.1016/j.ijbiomac.2012.02.031

Narayanan D, Jayakumar R, Chennazhi KP (2014) Versatile carboxymethyl chitin and chitosan nanomaterials: a review. Wiley Interdiscip Rev: NanomedNanobiotechnol 6(6): 574-598, DOI.org/10.1002/wnan.1301.

Novac O, Lisa G, Profire L, Tuchilus C, Popa MI (2014) Antibacterial quaternized gellan gum-based particles for controlled release of ciprofloxacin with potential dermal applications. Mater Sci Eng C 35: 291-299. DOI: $\underline{10.1016 / \mathrm{j} . \mathrm{msec} .2013 .11 .016}$

Ovenden C, Xiao H (2002) Flocculation behaviour and mechanisms of cationic inorganic microparticle/polymer systems. Colloids Surf A 197(1-3): 225-234, DOI: 10.1016/S0927$\underline{7757(01) 00903-7}$ 

characterization of cationic corn starch with a high degree of substitution in dioxane-

DOI:

Ponnusami V, Vikram S, \& Srivastava SN (2008) Guava (Psidium guajava) leaf powder: novel adsorbent for removal of methylene blue from aqueous solutions. J Hazard Mater 152(1): 276-286. DOI: 10.1016/j.jhazmat.2007.06.107

Prado BM, Kim S, Özen BF, Mauer LJ (2005) Differentiation of carbohydrate gums and mixtures using Fourier transform infrared spectroscopy and chemometrics. J Agric Food Chem 53(8): 2823-2829. DOI: 10.1021/jf0485537

Rahul R, Jha U, Sen G, Mishra S (2014) Carboxymethyl inulin: A novel flocculant for wastewater treatment. Int J BiolMacromol 63: 1-7. DOI: 10.1016/j.ijbiomac.2013.10.015 Rao KV (1995) Inhibition of DNA synthesis in primary rat hepatocyte cultures by malachite green: a new liver tumor promoter. Toxicol Lett 81: 107-113. DOI: $10.1016 / 0378-4274(95) 03413-7$

Rao KVK (1995)Inhibition of DNA synthesis in primary rat hepatocyte cultures by malachite green: a new liver tumor promoter. Toxicol Lett 81(2-3): 107-113. DOI: $10.1016 / 0378-4274(95) 03413-7$

Reed BE, Matsumoto MR, Jensen JN, Viadero R, Lin W (1998) Physicochemical processes. Water Environ Res 70(4): 449-473. 
Sener S (2008) Use of solid wastes of the soda ash plant as an adsorbent for the removal of anionic dyes: equilibrium and kinetic studies. Chem Eng J 138: 207-214. DOI: 10.1016/j.cej.2007.06.035

Sharma D, Kumar V, Nautiyal R, Sharma P (2020b) Synthesis and characterization of quaternized Cassia tora gum using Taguchi L'16 approach. Carbohyd. Polym 232: 115731. DOI: 10.1016/j.carbpol.2019.115731F

Sharma D, Kumar V, Sharma P (2020a) Application, Synthesis, and Characterization of Cationic Galactomannan from Ruderal Species as a Wet Strength Additive and Flocculating Agent. ACS omega 5(39): 25240-25252. DOI: 10.1021/acsomega.0c03408

Sirviö J Honka A, Liimatainen H, Niinimäki J, Hormi O (2011) Synthesis of highly cationic water-soluble cellulose derivative and its potential as novel biopolymeric flocculation agent. CarbohydrPolym 86(1): 266-270,

DOI: $\underline{10.1016 / j . c a r b p o l .2011 .04 .046}$

Srivastava S, Sinha R, Roy D (2004) Toxicological effects of malachite green. AquatToxicol 66(3): 319-329. DOI: 10.1016/j.aquatox.2003.09.008

Su L, Ou Y, Feng X, Lin M, Li J, Liu D, Qi H (2019) Integrated Production of Cellulose Nanofibers and Sodium Carboxymethylcellulose through Controllable Ecocarboxymethylation under Mild Conditions. $\quad$ ACS Sustainable Chem Eng 7(4): 37923800. DOI: $10.1021 /$ acssuschemeng. 8 b04492

Suopajärvi T, Koivuranta E, Liimatainen H, Niinimäki J (2014) Flocculation of municipal wastewaters with anionic nanocelluloses: Influence of nanocellulose characteristics on floc morphology and strength. $\quad J \quad$ Environ Chem Eng 2(4): 2005-2012. DOI: 10.1016/j.jece.2014.08.023 

treatment of municipal wastewater based on anionizednanocelluloses. Chem Eng J 231: 59-67. DOI: 10.1016/j.cej.2013.07.010

Tako M, Tamaki Y, Teruya T (2018) Discovery of Unusual Highly Branched Galactomannan from Seeds of Desmanthusillinoensis. J BiomaterNanobiotechnol 9(02): 101-116. DOI: 10.4236/jbnb.2018.92009

Thombare N, Jha U, Mishra S, Siddiqui MZ (2016) Guar gum as a promising starting material for diverse applications: A review. Int J BiolMacromol 88: 361-372, DOI: 10.1016/j.ijbiomac.2016.04.001

Tutar M, Aydin H, Yuce C, Yavuz N, Bayram A (2014) The optimisation of process parameters for friction stir spot-welded AA3003-H12 aluminium alloy using a Taguchi orthogonal array. Mater Des 63: 789-797. DOI: 10.1016/j.matdes.2014.07.003

650 Wang L, Liang W, Yu J, Liang Z, Ruan L, Zhang Y (2013) Flocculation of Microcystis aeruginosa using modified larch tannin. Environ Sci Technol 47(11): 5771-5777. DOI: $10.1021 / \mathrm{es} 400793 x$

652

Wang Y, Xie W (2010) Synthesis of cationic starch with a high degree of substitution in an ionic liquid. CarbohydrPolym 80(4): 1172-1177. DOI: $\underline{10.1016 / j . c a r b p o l .2010 .01 .042}$

Xie Y, Yan B, Xu H, Chen J, Liu Q, Deng Y, Zeng H (2014) Highly regenerable musselinspired Fe3O4@ polydopamine-Ag core-shell microspheres as catalyst and adsorbent for methylene blue removal. ACS Appl Mater Interfaces 6(11): 8845-8852. DOI: 10.1021/am501632f 

polysaccharides: Synthesis, characterization, structure activity relationships of action. Int J BiolMacromol132: 970-977. DOI: 10.1016/j.ijbiomac.2019.03.213

Yan L, Tao H, Bangal PR (2009) Synthesis and flocculation behavior of cationic cellulose prepared in a NaOH/urea aqueous solution. Clean-Soil Air Water 37(1): 39-44. DOI: $10.1002 /$ clen.200800127 Yang WP, Tarng YS (1998) Design optimization of cutting parameters for turning cellulose prepared in a NaOH/urea aqueous solution. Clean-Soil Air Water 37(1): 39-44. DOI: $10.1002 /$ clen.200800127 Yuen SN, Choi SM, Phillips DL, Ma CY (2009) Raman and FTIR spectroscopic study of carboxymethylated non-starch polysaccharides. Food Chem. 114(3): 1091-1098. DOI: 10.1016/j.foodchem.2008.10.053 
Figures

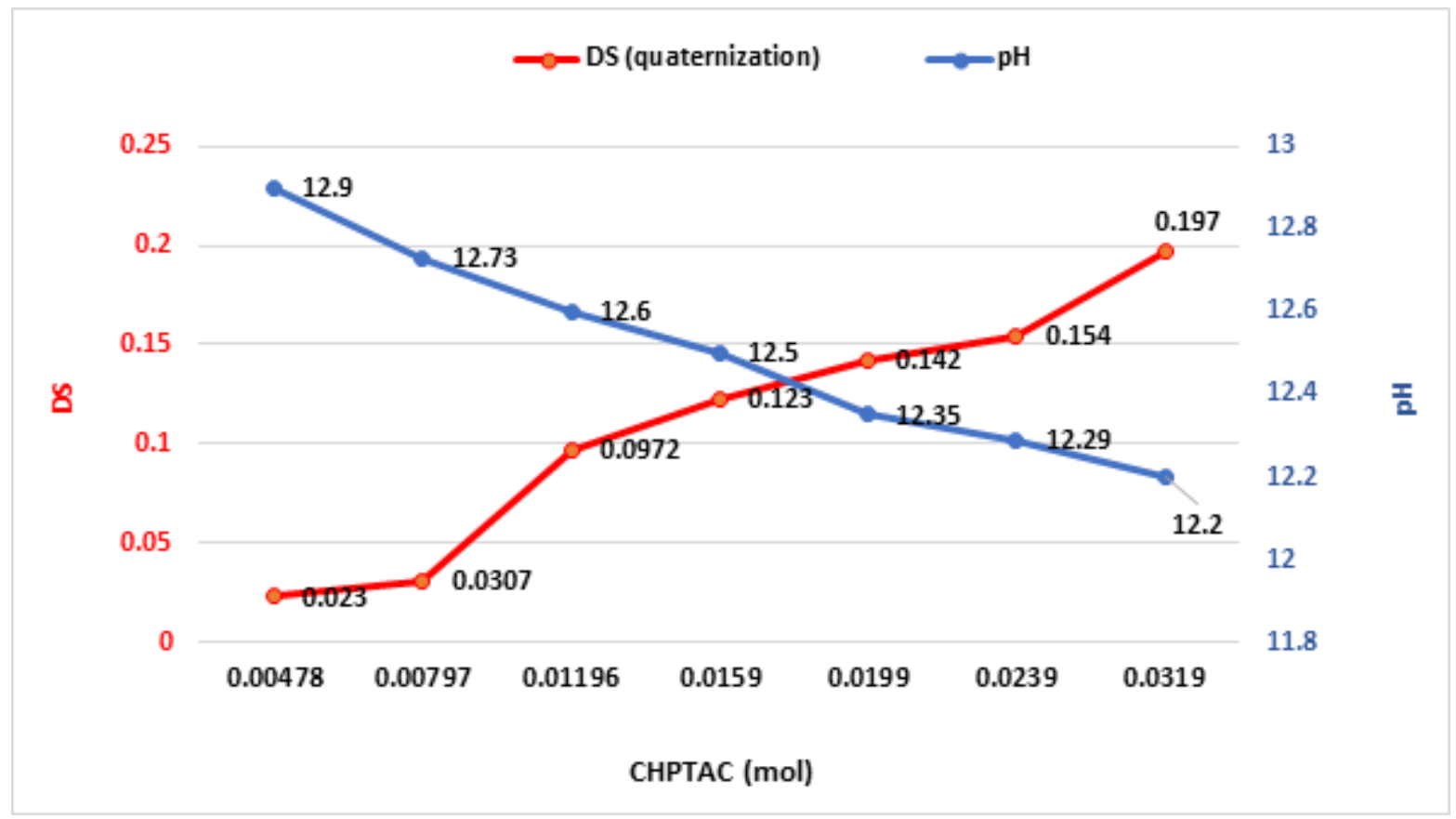

Figure 1

Effect on DS (quaternisation) and $\mathrm{pH}$ on varying amount of CHPTAC 
a $\quad$ i
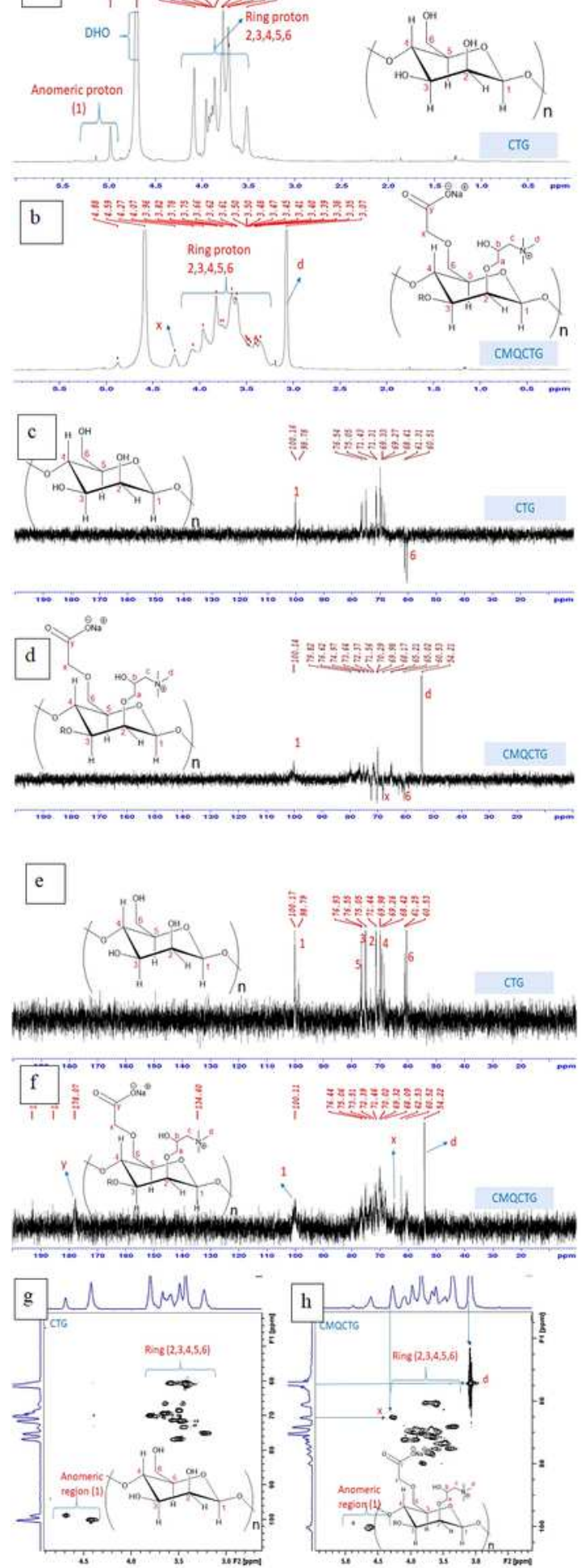

Figure 2

NMR spectrum of CTG and CMQCTG: (a\& b) 1H-NMR spectrum; (c \& d) 13C-NMR spectrum; (e \& f) DEPT Spectrum; (g \& h) HSQC Spectrum 

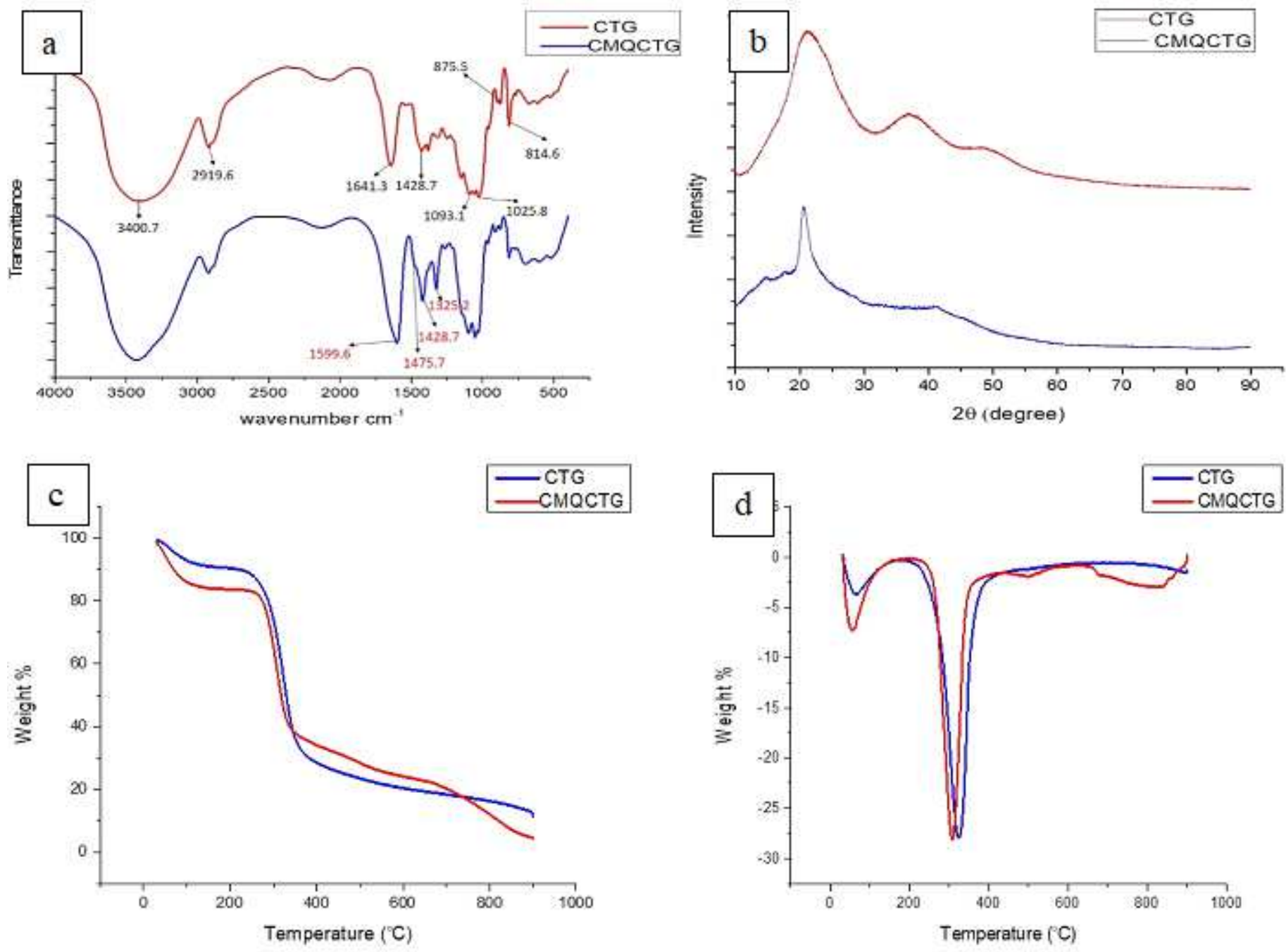

Figure 3

(a) FT-IR spectra of CTG \& CMQCTG (b) XRD of CTG and CMQCTG (c) TGA of CTG \& CMQCTG (d) DTG of CTG \& CMQCTG
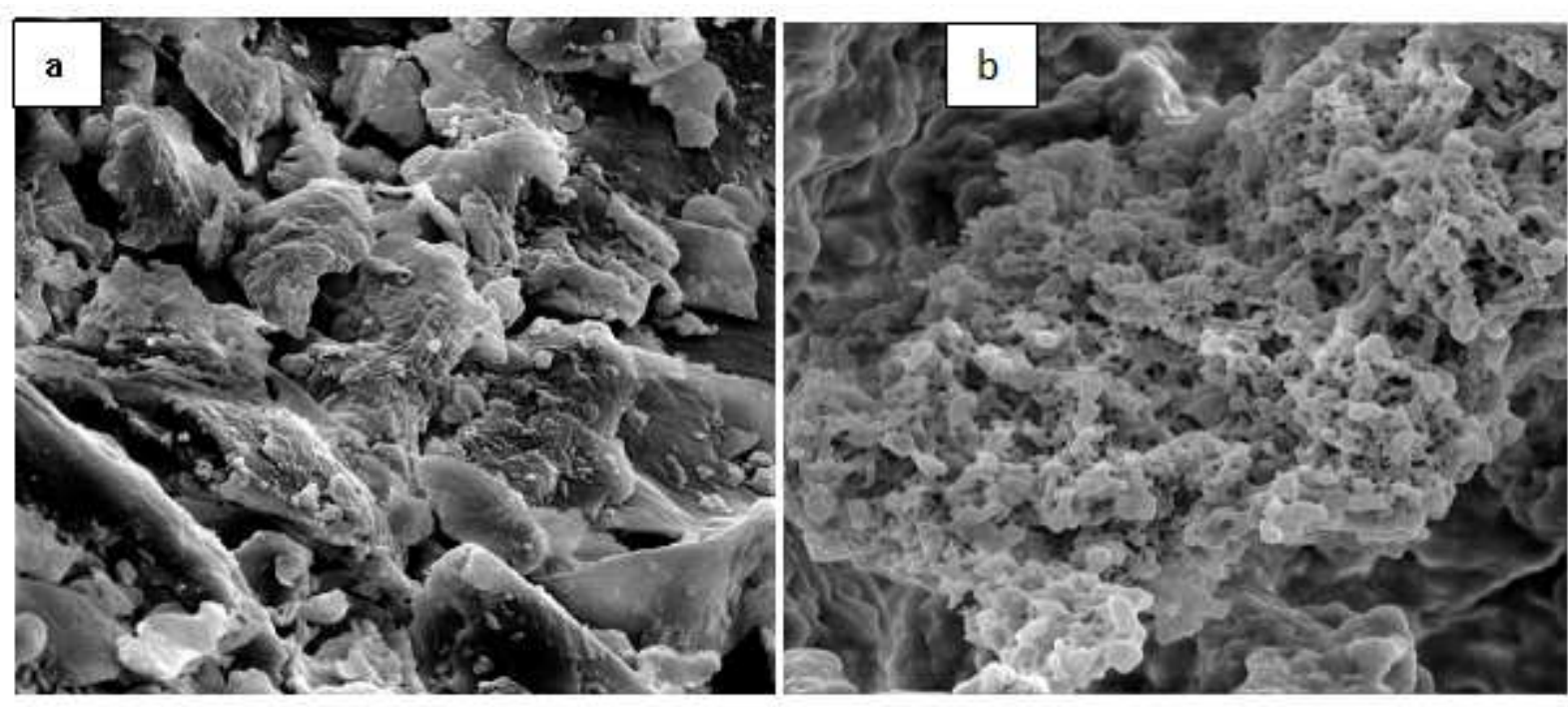

Figure 4 
(a) FESEM image of (a) CTG and (b) CMQCTG
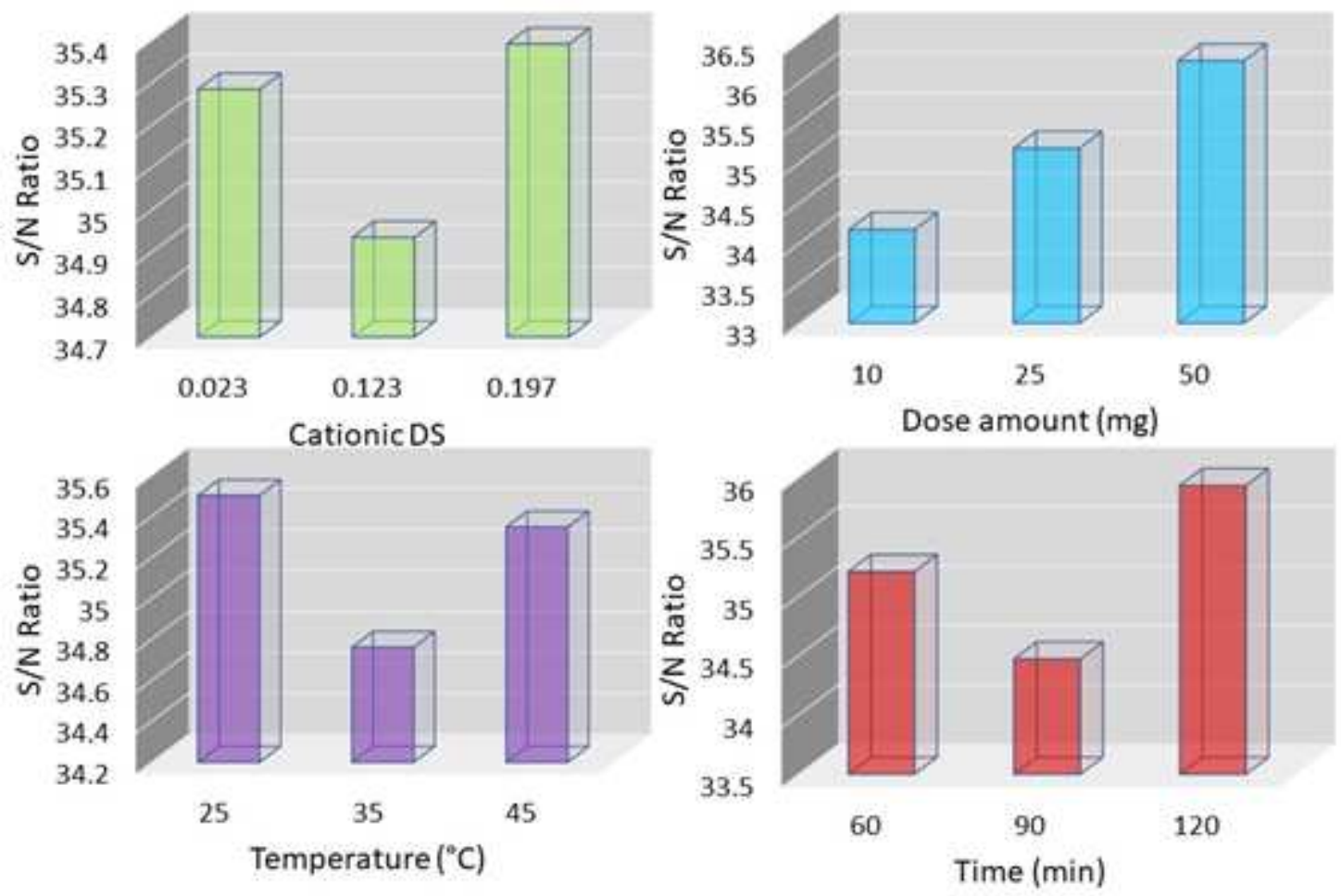

Figure 5

Effect of different parameters on Malachite Green dyes with respect to $\mathrm{S} / \mathrm{N}$ ratio
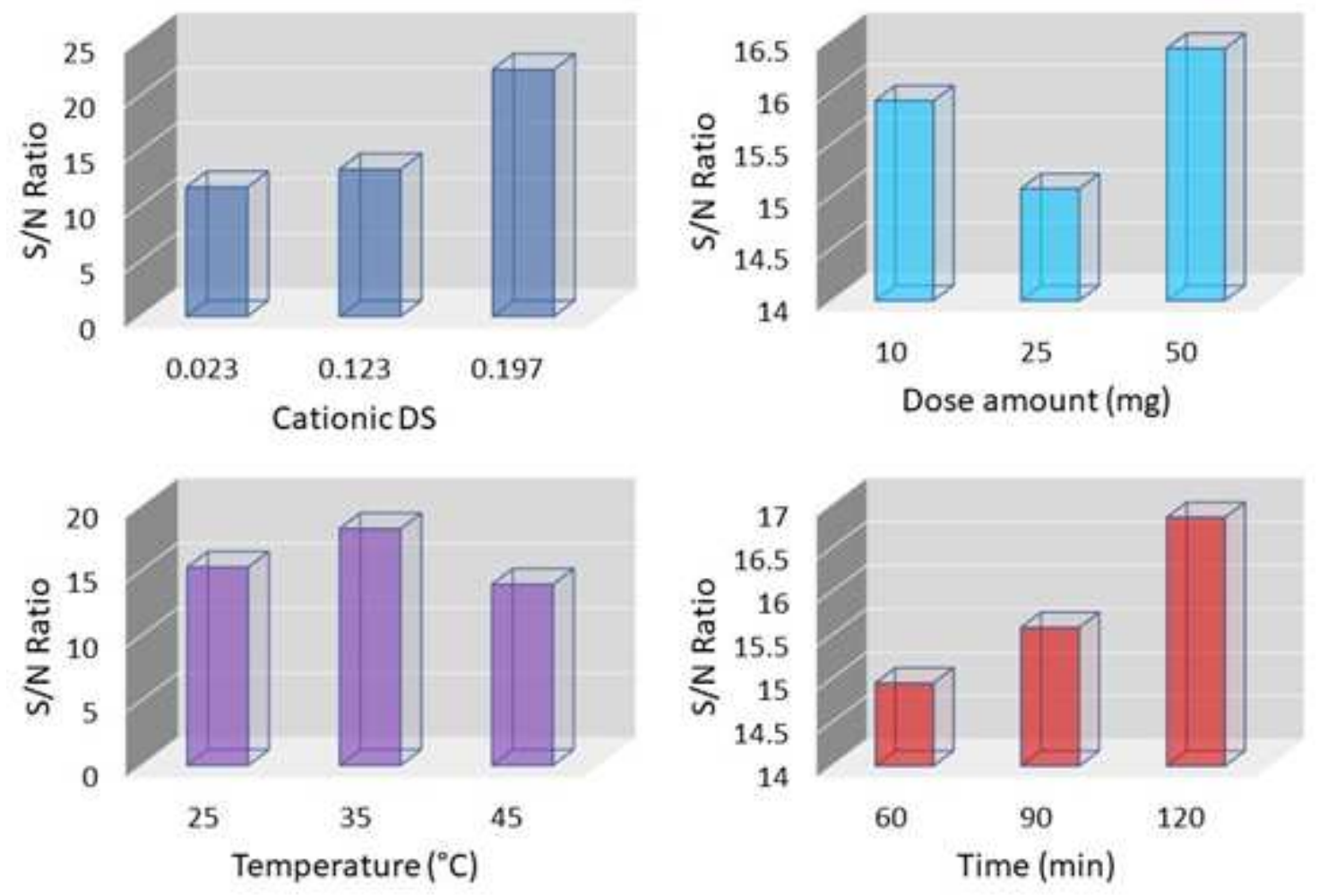

Figure 6 
Effect of different parameters on Congo Red dyes with respect to S/N ratio

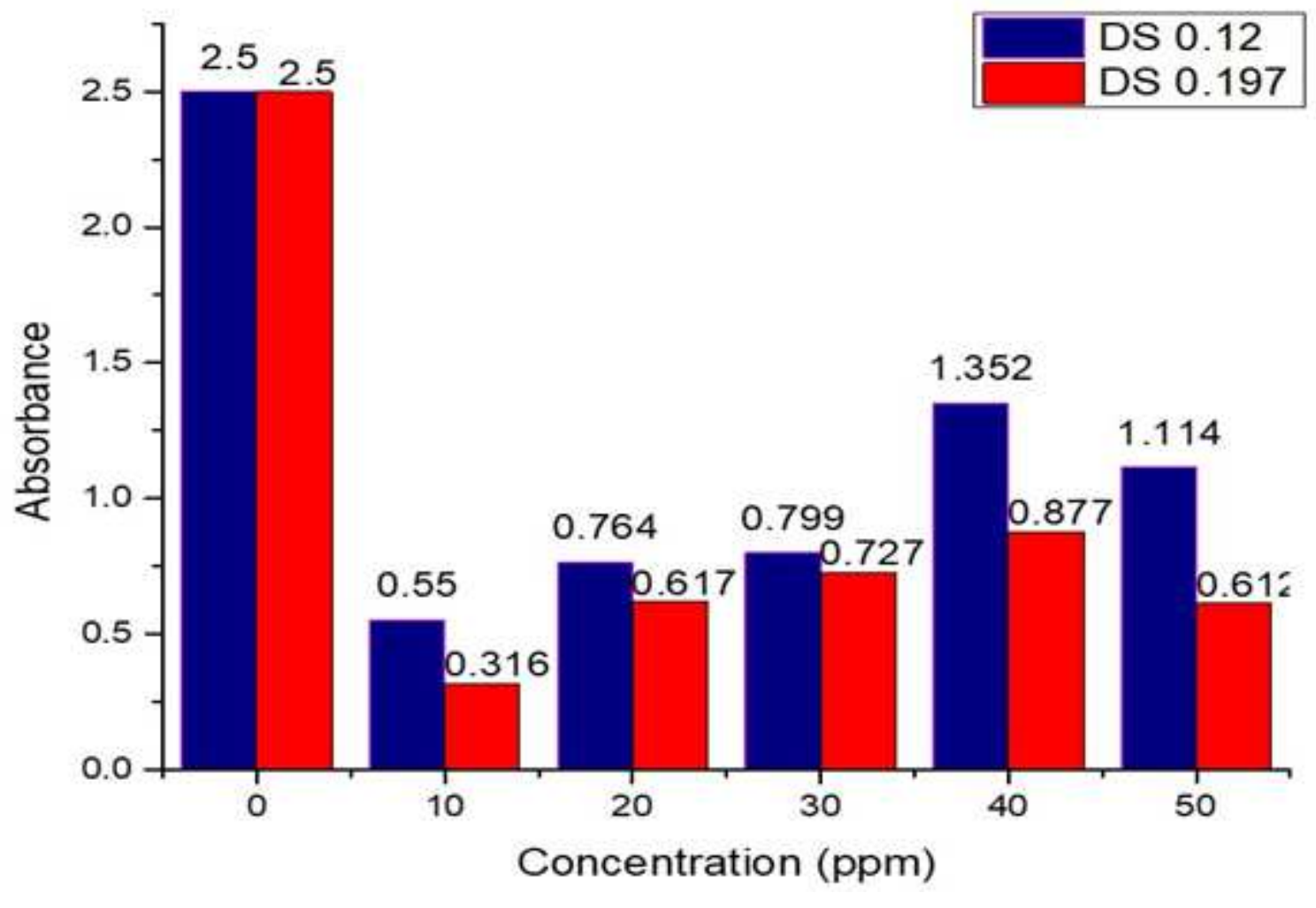

Figure 7

Flocculation performance of CMQCTG

\section{Supplementary Files}

This is a list of supplementary files associated with this preprint. Click to download.

- Scheme01.png 